\title{
YOUTH EMPLOYMENT IN EUROPE: INSTITUTIONS AND SOCIAL CAPITAL EXPLAIN BETTER THAN MAINSTREAM ECONOMICS
}

\author{
Bruno Contini \\ University of Torino and LABORatorio R. Revelli \\ Collegio Carlo Alberto \\ November 2009
}

\begin{abstract}
Why did employment growth - high in the last decade- take place at the expense of young workers in the countries of Central and Southern Europe ? This is the question addressed in this paper. Youth unemployment has approached or exceeded $20 \%$ despite a variety of factors, common to most EU countries. According to neo-classical economics all would be expected to exert a positive impact on its evolution: population ageing and the demographic decline, low labor cost of young workers, flexibility of working arrangements, higher educational attainment, low unionization of young workers, early retirement practices of workers 50+. But neither seems to provide a convincing explanation. Historically based institutions and political tradition, cultural values, social capital - factors that go beyond the standard explanation of economic theory - provide a more satisfying interpretation.
\end{abstract}

Keywords: youth employment, unemployment, social capital, institutions.

JEL Codes: J, J0, J1, J6. 


\section{Introduction}

Why did employment growth - high in the last decade- take place at the expense of young workers in the countries of Central and Southern Europe? This is the question addressed in this paper. Youth unemployment has approached or exceeded $20 \%$ despite a variety of factors, common to most EU countries. According to neo-classical economics all would be expected to exert a positive impact on its evolution: population ageing and the demographic decline, low labor cost of young workers, flexibility of working arrangements, higher educational attainment, low unionization of young workers, early retirement practices of workers 50+. But neither seems to provide a convincing explanation. Historically based institutions and political tradition, cultural values, social capital - factors that go beyond the standard explanation of economic theory - provide a more satisfying interpretation.

The paper is organized as follows. Par. 1 introduces the background story and surveys a few of the main contributions to the problem. Par.2 illustrates two potential driving factors of the employment differentials: demography and school attainment in par. 2.1; complementarity and substitution between youth on one side and women and the young elderly on the other in par. 2.2. A preliminary examination of how the welfare state and the institutions impact on young people's labor market is addressed in par. 3 . Wage rigidity is the argument of par. 4; the role of mobility and flexibility of par. 5 . In par. 6 I survey a few papers that deal with one of the basic questions raised in connection to flexibility: "are fixed term contracts efficient ports of entry to permanent positions ?". In Par. 7, towards the end of my exploration, I reach the conclusion that neo-classical economics does not provide convincing explanations of the indeed remarkable cross-country differences. Alternative explanations to the persistence of employment differentials call for categories that are too often absent from economic analysis: institutions, rule of law, civic values, political tradition. A short conclusion is left for Par. 8.

\section{The background story}

The problem of European unemployment has spurred an immense amount of deep thought among the academics, especially in the last decades of the century when it became clear that the EU natural unemployment rate was climbing from a relatively untroubled 5-6\% to a worrisome 8-9\% and progressively leading to hysteresis. A variety of reasons had been given to explain this development: (i) the interactions of supply shocks with real and monetary rigidities (M. Bruno and J. Sachs, 1985) and with differences in collective bargaining structures (L. Calmfors and A.Driffil, 1988); (ii) the tight monetary policies in the Eighties that curbed inflation and had adverse effects on employment (C. Bean, 1993); the persistence mechanisms with lasting effects on unemployment, in first place the role of insiders in collective bargaining (A. Lindbeck and D. Snower, 1990; O.Blanchard and L. Summers, 1989); the adverse effect of long term unemployment on human capital, skill obsolescence and stigma (R. Layard and S. Nickell, 1987); the labor market rigidities (OECD Jobs Study, 1994), accompanied by 
lower trade barriers and higher integration, all leading towards increased turbulence of the world economy and ill adapted institutions (G. Bertola et al., 1990 and 1994).

Since the turn of the millennium, however, while overall employment was back on the rise, youth employment was still lagging behind in many EU member countries, and a source of considerable preoccupation. As a matter of fact the European Union has had youth employment on the agenda for at least two decades. Since the mid Eighties, all EU countries have moved in the direction of labor market deregulation and contract flexibility, with the principal aim of enhancing job opportunities for the young.

As of today about $37 \%$ of young Europeans aged 15-24 are in employment, with huge differences among countries ranging from $68 \%$ in the Netherlands and $21 \%$ in Hungary. Many youth of this age group are still in education, be it general education, vocational education or training. During 2005-2008, characterized by a positive business cycle, progress has been made in reducing youth unemployment which fell on EU-27 average from $18.3 \%$ in 2005 to $15.3 \%$ in 2007 . Nonetheless, differences among member countries are remarkable, with several countries struggling with youth unemployment rates above $20 \%$.

The problem of making room for new and safe job opportunities is not limited to young people. Especially in Southern Europe it touches upon the so-called "secondary" segment of the workforce: women, the "young elderly" (50+) forced to take early retirement, the unskilled segment of the workforce including the vast majority of immigrants, all belong to the weak fringes of the labor force for which better working conditions are badly needed.

The risk of progressive dualization of the labor market has been the object of authoritative warnings (Blanchard and Landier, 2001; G. Saint-Paul, 2004): while the insiders, workers with permanent open-end contracts, are relatively sheltered by the welfare institutions, the protection afforded to the outsiders is minimal. The number of outsiders, especially the young ones, has risen at formidable rate in the last decade: even at the age of 29 only half of the EU population is in a stable employment position: involuntary part-time or limited contract work remains a big problem also in this age group, as it puts serious constraints on one's life style impacting on morale, mental health, expectations, delaying family formation and fertility, etc.

The accumulation of human capital is at risk: in the short run higher flexibility may generate suitable matches between employers and workers and, possibly, higher efficiency in the economy. In the long run, however, a higher turnover decreases the incentive to invest in human capital, both from the company's and the worker's point of view, thereby reducing productivity and hampering economic performance and future growth.

A comparative look at the growth rates of employment and GNP in the 2000-2008 period (Tab. 1) sheds some light on the medium-long run issue, and provides a useful background for the rest of the story. 
Tab. 1 OECD: 2000-2008 growth rates and multi-factor productivity (MFP)

\begin{tabular}{|l|l|l|l|l|l|l|}
\hline & EMPL. & $\begin{array}{l}\text { GNP } \\
\text { CONSTANT } \\
\text { PRICES }\end{array}$ & $\begin{array}{l}\text { LABOR } \\
\text { PRODUCTIVITY }\end{array}$ & $\begin{array}{l}1985-95 \\
\text { MFP }\end{array}$ & $\begin{array}{l}1995-07 \\
\text { MFP }\end{array}$ & $\begin{array}{l}2001-07 \\
\text { MFP }\end{array}$ \\
\hline AU & 8,2 & 23,4 & 15,1 & & & \\
\hline BE & 6,7 & 16,0 & 9,3 & & & \\
\hline DK & 3,9 & 10,4 & 6,5 & 1,5 & & 0,6 \\
\hline FL & 8,4 & 25,0 & 16,6 & 1,3 & 0,3 & 1,6 \\
\hline FR & 5,8 & 14,1 & 8,3 & 1,7 & 2,1 & 1,0 \\
\hline GE & 6,0 & 9,7 & 3,7 & 1,4 & 1,1 & 0,6 \\
\hline GR & 11,8 & 35,8 & 24,0 & & 1,0 & \\
\hline IRE & 26,1 & 43,4 & 17,3 & 3,3 & 3,5 & 2,5 \\
\hline IT & 10,3 & 7,3 & -3 & 1,3 & 0,1 & $-0,7$ \\
\hline NL & 7,7 & 16,5 & 8,8 & 1,0 & 0,8 & 0,7 \\
\hline POR & 3,1 & 7,9 & 4,8 & & 1,2 & 0,3 \\
\hline SP & 29,9 & 28,0 & -1.9 & & 0,1 & $-0,1$ \\
\hline SWE & 10,4 & 19,8 & 9.4 & 0,5 & 1,8 & 2,7 \\
\hline UK & 8,5 & 20,4 & 11,9 & 1,0 & 1,2 & 1,2 \\
\hline
\end{tabular}

As mentioned before, employment witnessed a substantial increase since the turn of the millennium, with the exception of Denmark and Portugal. Spain and Ireland top the list with peaks over $25 \%$, but many other countries approach or exceed a $10 \%$ growth rate. As a consequence unemployment rates have declined almost everywhere. The intercountry variability of GNP growth has been high. The interesting features come from average productivity, measured by the difference between GNP growth and employment growth: many of the smaller countries show an impressive outcome (with the UK and, to some extent France, performing very well too). Labor productivity growth in Spain and Italy, instead, became negative, and so did multi-factor productivity since 2001. This finding suggests that the wide utilization of high-flexibility, low-pay contracts in Spain and Italy - enhanced by the labor market reforms of the last twenty years - may have been among the driving force behind these developments. ${ }^{1}$

In the next decades demographic trends ought to improve the work perspectives of young people: the cohorts of the baby-boomers will begin to retire by 2020-25, and their replacement will increase the demand of young workers. On the other hand, the labor shortage will also spur new and massive migration inflows of largely unskilled people from non EU-countries with high fertility rates. This will be a cause of additional governance problems for the European Union, as social unrest will not cease to hide behind the door.

The key question is therefore: why did employment growth - high in the last decade- take place at the expense of young workers in the countries of Central and Southern Europe.

\footnotetext{
${ }^{1}$ Additional evidence of Italy's weak position vis-à-vis the rest of its direct eu competitors is signaled by the pattern of real wages: stagnant since the early nineties, while in the rest of Europe they were increasing by $10 \%$ in the market sectors, and by $20 \%$ and over in manufacturing.
} 
From a cross-country, comparative perspective, these long developments defy simple economic explanations. Youth unemployment has approached or exceeded $20 \%$ despite a variety of factors, common to most EU countries, that might be expected to positively impact on its evolution: ageing and the dramatic demographic decline after the baby boom, the low labor cost of young workers relative to adult ones, the flexibility of the new working arrangements, the higher educational attainment, the low unionization of young workers, the early retirement practices of workers 50+ (often negotiated with the unions with the intent of making room for new young entries). Are these developments the consequence of over-optimistic expectations on the agenda of labor market reform and regulation aimed at enhancing youth employment (and, in some cases, somewhat mismanaged implementation), or, instead, may such negative outcomes have been exacerbated by traditional demand and supply factors? The former is, in my opinion, a more convincing argument than the latter, although neither one goes at the deep root of the issue. The specific cultural and institutional framework - factors that go beyond the standard explanation of economic theory - provide a more robust and convincing interpretation. Some institutions are more conducive to positive labor market outcomes than others. The Nordic countries, Denmark in particular, have been pointed as the top performers long before joining the EU, but there too questions arise: to what extent is it the heritage of the social-democratic values and culture (which have not been lost in spite of adverse electoral outcomes), or does their performance derive from the "small economy - low population density" advantage ${ }^{2}$ ? The Mediterranean countries, on the other hand, are the worst performers along all the dimensions in a comparative examination.

My exploration rests on simple associations between macro indicators of labor market performance, demography and institutional characteristics. To these I add the World Bank indicators of "values" and "rules of law" which provide support to the sociopolitical-cultural explanation of these developments. While such a rough empirical test cannot yield a complete and articulated explanation, it does provide insightful flashes that sketch the story. In particular, it highlights that the best performing countries look "best" in almost all dimensions considered, including (and, perhaps, especially) the sociopolitical-cultural ones, while the opposite holds for the "worst" performing ones. This finding (probably not surprising to a political scientist) suggests that the driving forces of labor market outcomes lie in the historical-socio-political-cultural sphere, more than in economy-related events and reform. If this is the case, while sound economic reform and regulation may have a positive impact at the margin, they will fail to achieve the main target for years to come. A reversal of demographic trends, the not-so-distant retirement of the baby boom generation and a successful, although very difficult, integration of immigration flows, may lead in the right direction if accompanied by intelligent and very forward looking policies.

\footnotetext{
2 I will not elaborate on this problem here: it is a different and difficult one. Consider, for instance, the Netherlands: it shares the social democratic values as the Scandinavian countries, and it is "small". yet, its population density is the highest in Europe. Nor is there any evidence that Scandinavian citizens are "happier" than other Europeans (some indicators - alcohol consumption, suicide rate - rather suggest the contrary).
} 


\section{A bird's eye view of cross-country comparisons}

Multivariate analysis would obviously help the task, but falls outside the scope of this short article aimed at proposing a simple tale of stylized facts of the European economies in a socio-political as well as economic perspective. In-depth econometric analysis at a higher level of territorial disaggregation would add to the explanation: big regional disparities exist within several EU countries (Italy, France, Germany, Spain, UK, and others too), reflecting differences of economic development, culture and social capital $^{3}$. This is a major research project in itself, not within reach for the time being. The data reported here come from three sources: the OECD (online) database, the World Values indicators, Eurostat and the EU SILC 2006 survey.

\subsection{Demography, participation ${ }^{4}$ and school attendance}

Demography is the main long run determinant of young people's labor supply. Demography declined all over Europe following the baby boom of the sixties, leading to a major shrinkage of youth labor supply. Participation rates fell too in parallel with demographic trends, but not as a direct consequence. Demography impacts on the size of the new cohorts, much less on young people's propensity to join the labor market. Among the driving forces that account for the falling participation - perhaps the most important of all - is the increase in school attendance ${ }^{5}$. In Southern Europe educational attainment in the Sixties and early Seventies was much lower than in Continental and Northern Europe, also, not only, as a consequence of the size of the agricultural sector that employed up to $40 \%$ of the workforce, including many teenagers. It began to catch

\footnotetext{
${ }^{3}$ It should be mentioned here the growing and important literature on public program evaluation which addresses a vast number of questions touching upon the effectiveness of institutional involvement. But evaluation of the impact of public policy - often restricted to measuring direct short run effects - is done via non parametric estimation on reduced forms that cannot explain the interplay between the socioeconomic environment and the institutions, which is at the heart of this exploration. In addition to the fact that institutions are multidimensional and reducing them to quantitative indexes is not an easy task.

4 Here and in what follows I use the term "youth participation" and "youth employment rates" almost interchangeably. The procedure would be incorrect if my focus were on cyclical movements - participation reflects labor supply, employment reflects demand. It is acceptable for long run comparative explorations: the two indicators are of the same order of magnitude and highly correlated. Moreover, while nowadays youth participation is relatively homogeneously estimated on the basis of EU-wide LFS questionnaires, this was not the case till the mid Nineties. As a consequence time series of participation rates are unreliable for cross-country comparisons. In addition, in many LFS's young individuals are often found who report to be seeking work but have not undertaken any recent action to find a job. Eurostat classifies them as inactive instead of members of the labor force, adding to the confusion. Employment rates are less sensitive to classification problems.

${ }^{5}$ Other factors have cyclically co-determined the falling labor participation of young cohorts: in first place a discouragement effect due to lack of aggregate demand, but mostly the adverse substitution effect of prime age workers (the baby boomers) whose cohorts were increasing at the same speed at which the younger ones were shrinking.
} 
up in the Seventies all over Europe, with an immediate impact on youth participation ${ }^{6}$. Fig. 1 shows the trends in demography and school attendance in 12 EU member states: a convenient indicator of the former is the youth dependency ratio (YDR), i.e. the ratio between the number of youth aged 15-24 to the population in working age 15-65 which declined by as much as $50 \%$ in 35 years; of the latter the share of youth aged 20-24 having attained secondary education $(\mathrm{SCH})$.

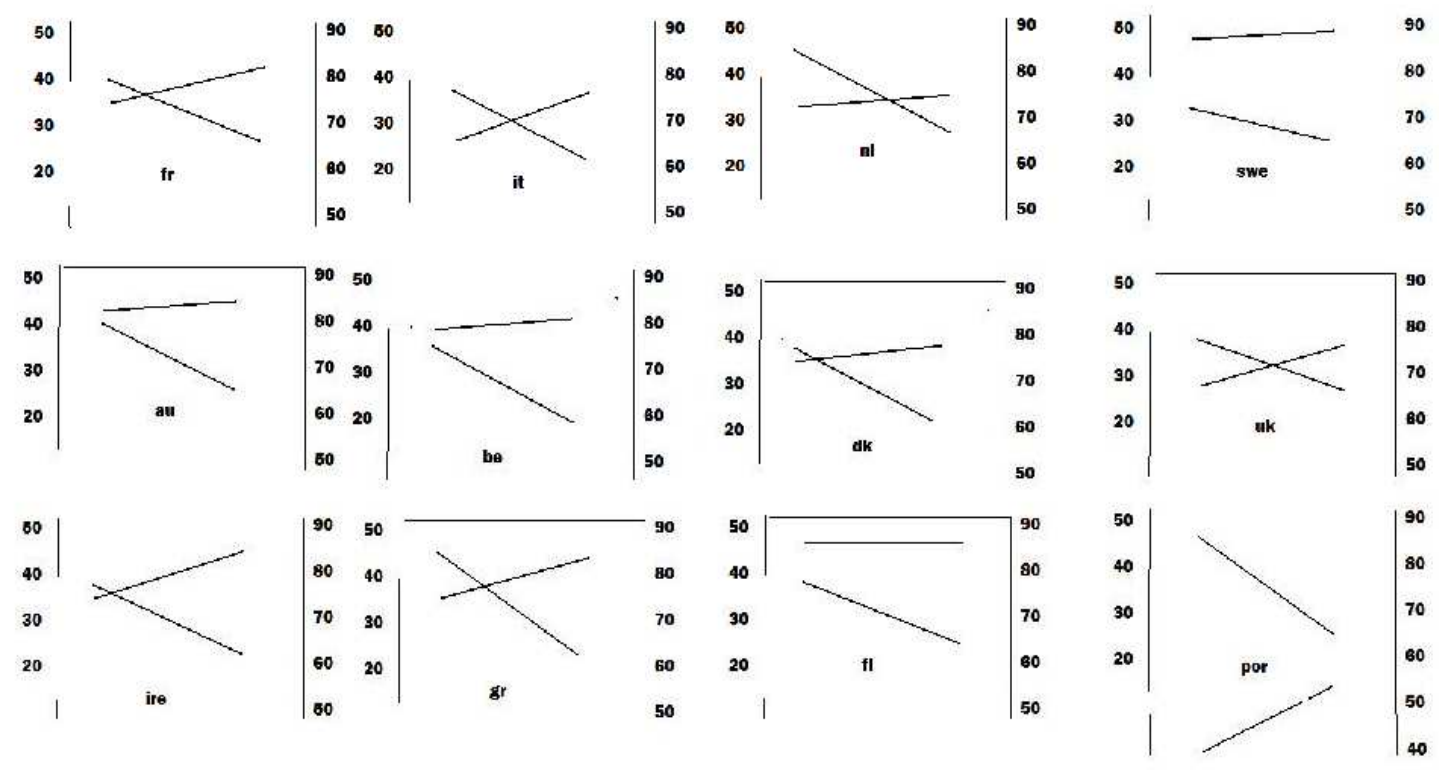

Fig. 1 Trends in demography (YDR 1970-2005) and school attainment (SCH: 1997 2007)

${ }^{6}$ The OECD 2004 rankings of educational attainment (including university degree) add to the picture of relative backwardness for Italy and Spain:

\begin{tabular}{|c|c|c|c|c|}
\hline 2004 & 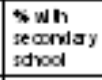 & $\begin{array}{l}O E C D \\
\text { auk ligg }\end{array}$ & \begin{tabular}{|l} 
wh wh \\
unversty \\
degree
\end{tabular} & OEcoratho \\
\hline DK & 81 & 6 & 32 & 5 \\
\hline FIN & 78 & 8 & 34 & 4 \\
\hline SUNE & 83 & 5 & 35 & 3 \\
\hline FR & 65 & 12 & 24 & 16 \\
\hline GER & 84 & 3 & 25 & 14 \\
\hline IRL & 63 & 16 & 28 & 10 \\
\hline IT & 48 & 18 & 11 & 20 \\
\hline $\mathrm{SP}$ & 45 & 19 & 26 & 12 \\
\hline UK & 65 & 13 & 26 & 12 \\
\hline USA & 88 & 1 & 39 & 1 \\
\hline JAP & 84 & 4 & 37 & 2 \\
\hline S-KOR & 74 & 10 & 30 & 7 \\
\hline
\end{tabular}


Demography and schooling are likely to converge in the long run as both are driven by deep structural dynamics, from relative backwardness to technological change and moderate affluence, affecting customs, fertility and literacy.

Demographic convergence is clearly displayed in fig. 2: there is a strong negative association between the initial YDR-1970 and the long differences $\triangle$ YDR 1970-2005: Sweden was the "oldest" country in 1970 (YDR at about 32\%), and YDR decreased the least (- 5 p.p.), Portugal was the "youngest" (YDR-70 $=48 \%$ ) and it decreased the most (- 24 p.p.). As a result, the between-country standard deviation of YDR is down to 2,98 in 2006 from 4,64 in 1970.

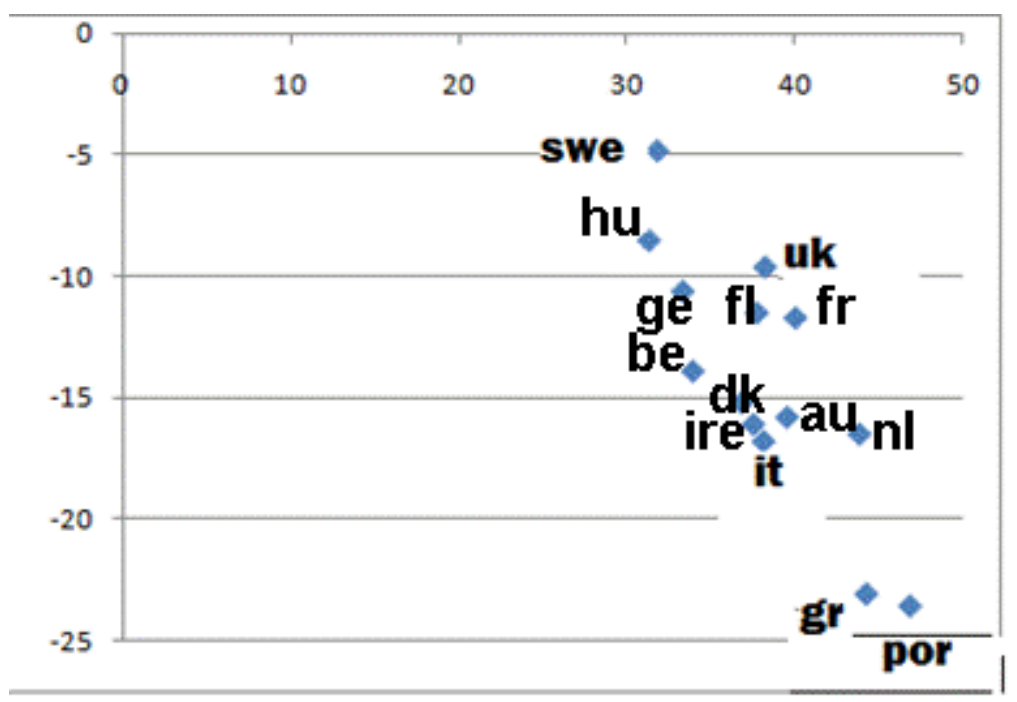

Fig. 2 Demographic convergence: $\triangle Y D R$ on the $y$-axis, YDR-70 on the $x$-axis

The convergence of school attainment is shown in fig. 3, where $\triangle \mathrm{SCH} 1997-$ 2007 is plotted against SCH-1997: Portugal had the highest employment share in agriculture in the early Seventies, with SCH at 40\%; in the 10-year time span 1997-2007, in parallel with a drastic decline of the agricultural sector, $\mathrm{SCH}$ gained 14 p.p. Spain and Italy were nearly at the same level in 1997 (SCH slightly over 50\%), but while Italy gained 14 p.p. by 2007, Spain lost a few points, a surprising outlier in the graph. At the other end we find the Scandinavian countries with SCH-1997 close to $90 \%$ and only a slight adjustment since. 


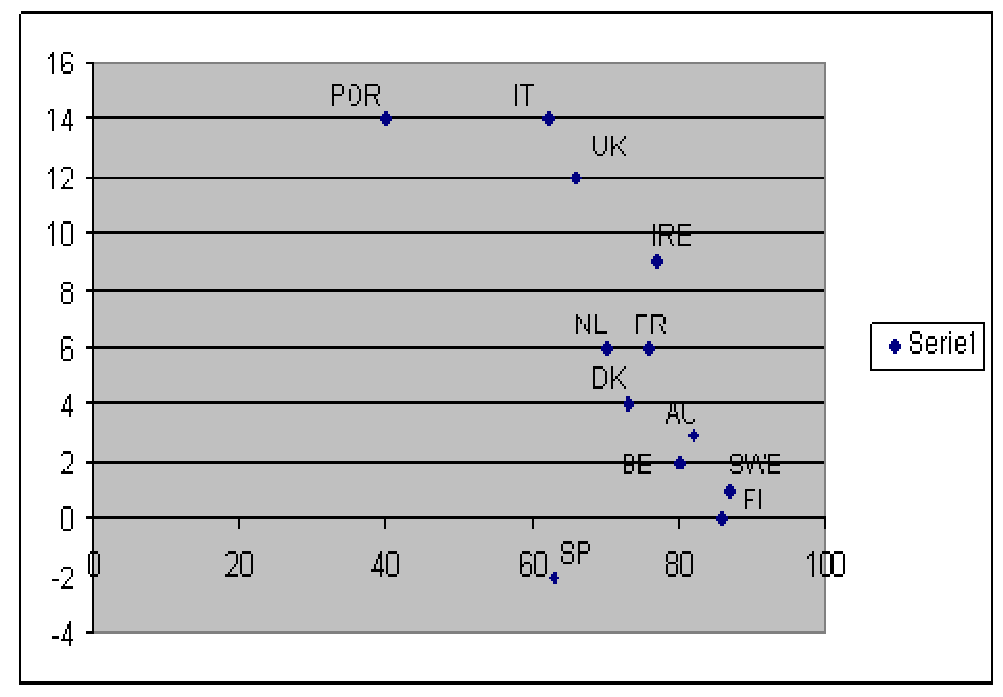

Fig. 3 Convergence in school attainment 1997-2007: SCH-1997 on the x-axis and $\triangle S C H$ 1997-2007 on the y-axis

High school attendance is the most important alternative option to teenage work: it obviously reduces youth labor market participation. The negative impact of $\Delta \mathrm{SCH}$ 1997-2007 on youth employment ( $\triangle$ YER1997-2007) emerges fairly well in fig. $4^{7}$. In the two countries where schooling shows the highest improvement in the recent decade (IT and POR) is found the largest decline in youth participation. At the opposite end the countries of Northern EU where positive $\Delta$ YER accompanied a slight increase in schooling.

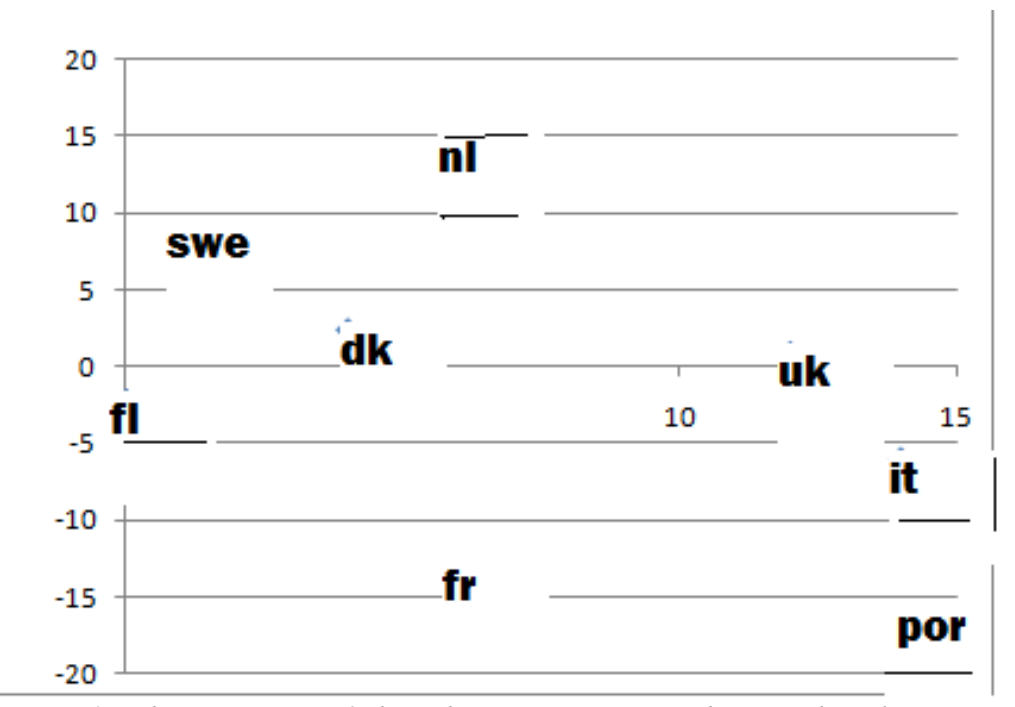

Fig. 4 The impact of the change in secondary school attainment $\triangle$ SCH 1997-2007 (x-axis) on the contemporaneous change of youth employment rates $\triangle Y E R$ 1997-2007 (yaxis).

7 Data on the attainment of secondary school degrees (\% on population in age 20-24) are available only since 1997. 
Are there reasons to expect that the demographic decline, in addition to the direct impact on the size of labor supply, might lead also to a decrease of youth participation? In principle, a negative association might hold if aggregate demand, average skills and productivity were constant throughout the years: where the demographic decline is tighter, a larger proportion of the fewer young people remained, would be called at work. All the more so, if aggregate demand, as it did, increased. Things look, however, surprisingly different: a slight, but positive correlation between $\Delta$ YDR and $\Delta$ YER emerges in fig. 5 (the Netherlands - with the largest increase in youth participation in spite of a big demographic decline - being a notable outlier ${ }^{8}$ ): Sweden lies in the N-E corner of the scatter with the smallest demographic change coupled with the largest increase in youth employment rate, while Portugal is at the opposite S-W corner.

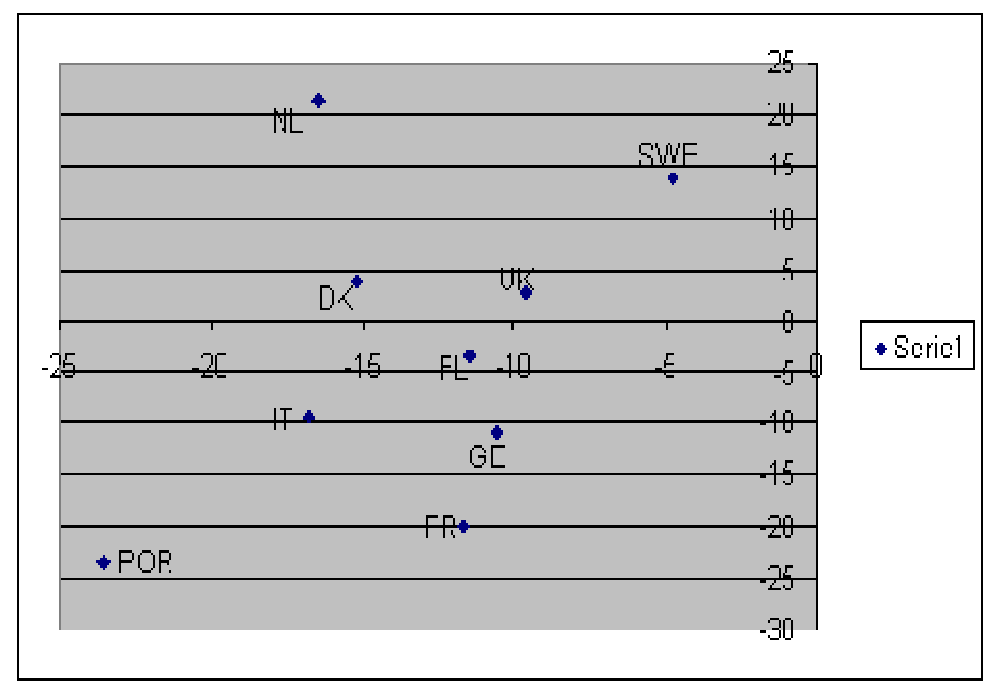

Fig. 5 A shift in labor participation? (y-axis: $\triangle Y E R ; x$-axis: $\triangle Y D R$ )

This pattern is strongly confirmed in fig. 6 where the demographic decline $\Delta$ YDR is highly (and positively) correlated with today's employment rate (YER-2007): the countries of Southern Europe experiencing the highest decline, have a lower proportion of young people at work, and are found in the S-W corner of the plot; those of Northern Europe are in the opposite corner. ${ }^{9}$

\footnotetext{
${ }^{8}$ As will argued later, the Dutch case hints at the fact that effective public programs may have a robust impact on youth employment.

${ }^{9}$ Notice that the correlation between YDR 2007 and YER 2007 is close to zero.
} 


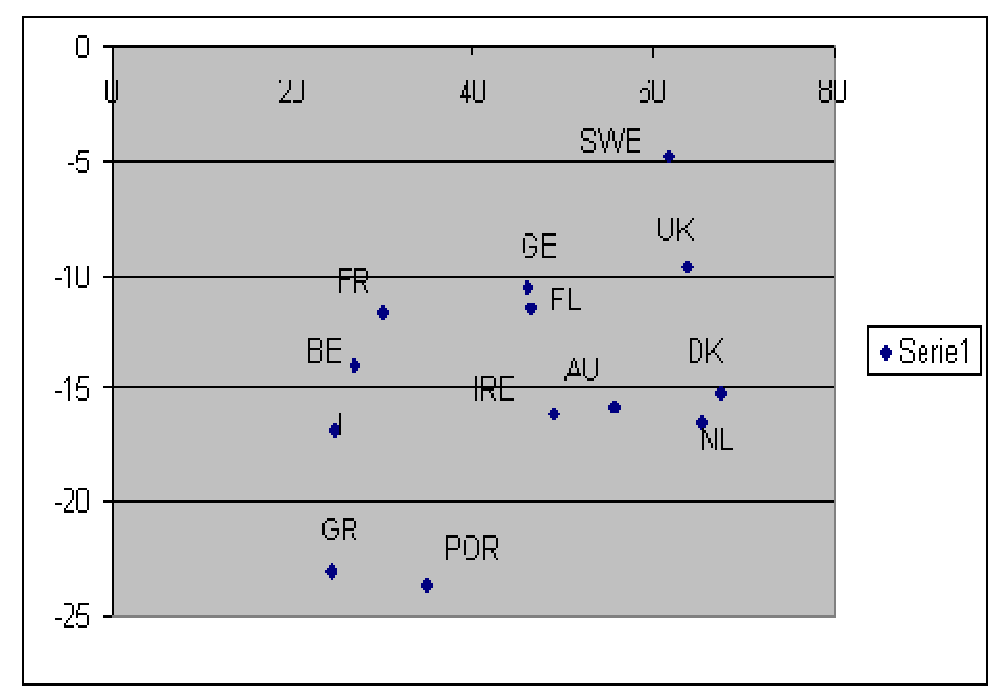

Fig. 6 - Demographic decline $\triangle$ YDR (x-axis) and youth employment YER 2007 (y-axis)

School attainment should be an important intervening variable for the explanation of this apparent puzzle, but may not be enough. Causality runs as follows: the demographic crisis leads to the shrinkage of youth labor supply, but not of participation; the improvement of educational attainment drives the downward trend in participation rates. Consider fig. 7 which is similar to fig. 6 , the only difference being that it plots the counterfactuals of youth employment rates, with schooling held at the 1997 level. ${ }^{10}$ In the four countries where schooling has marked the largest improvement - UK, France, Italy and Portugal - the "counterfactual" YER would have been higher by 3, 6, 5 and 9 p.p. respectively: quite a difference, but not sufficient to subvert the results so far discussed, nor those that will follow. ${ }^{11}$ In particular, fig. 6 and 7 look almost identical, offering no help to the discussion.

There is only one explanation left: inertia and persistence. Youth participation has very permanent features, much like other social phenomena to which I shall soon turn. Fig. 8 shows that the countries where youth employment was highest many years ago, are still firmly on top of the list, and the same holds for those that were at its bottom.

\footnotetext{
${ }^{10}$ This is done regressing YER on SCH and using the predicted values YER^ given SCH-1997.

11 All the bivariate regressions subsumed by the scatter plots of this paper would retain significance, although with a somewhat smaller slope coefficient.
} 


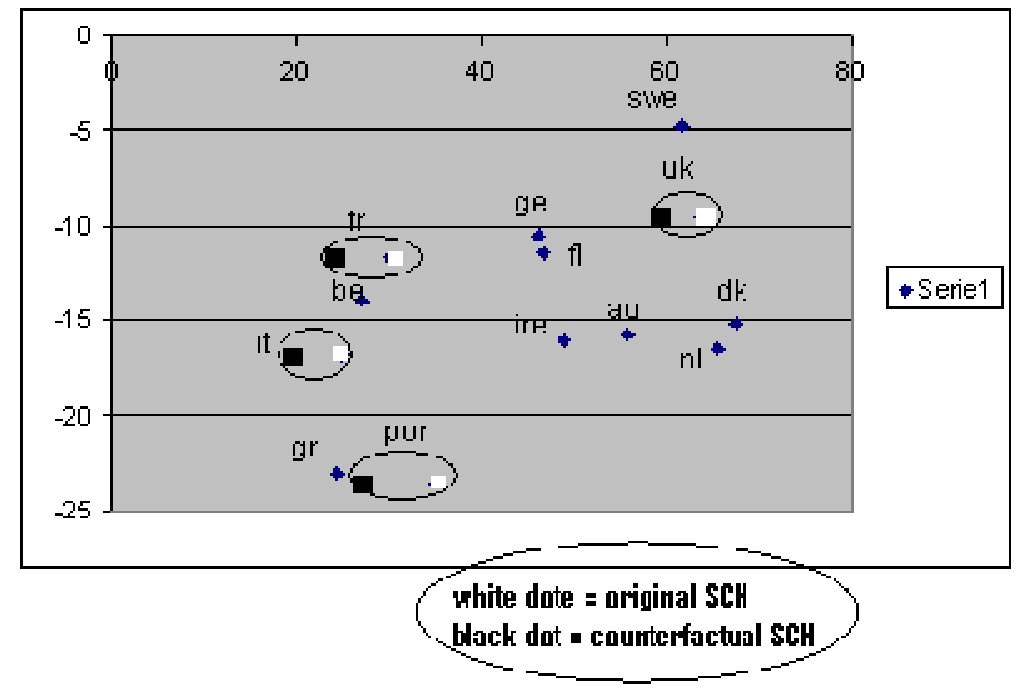

Fig. 7 Same as fig. 6, with counterfactual SCH. The shaded dots are only negligibly different from the original ones.

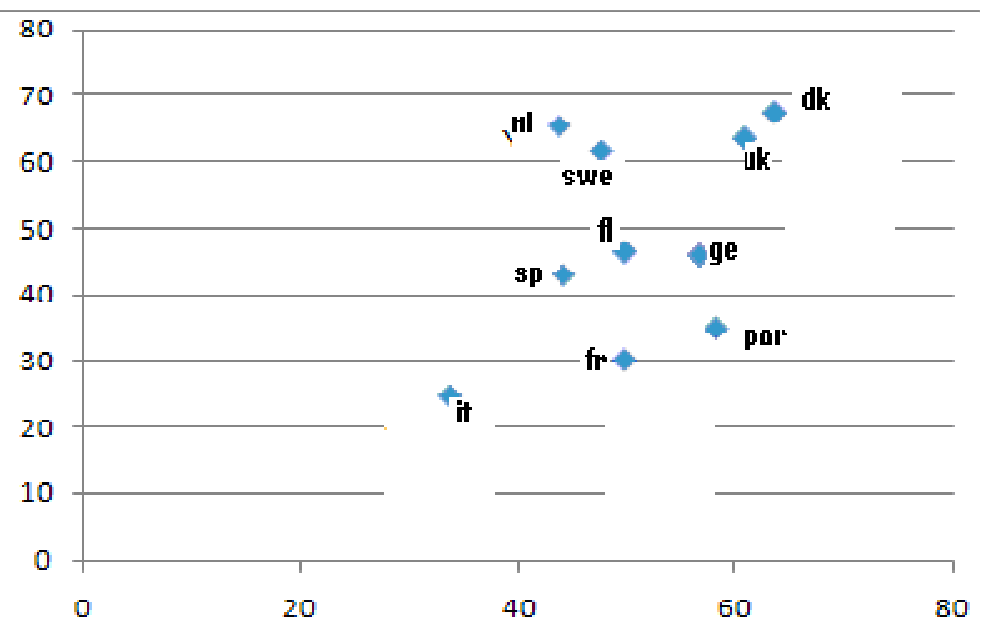

Fig. 8 - Youth emplayment rate YIR 1980 (x-axis) vs. YR 2007 (Y-axis)

\subsection{Young workers: substitutes or complements?}

The impact of demography and schooling on youth employment is, at this stage, fairly clear. The question that need be answered now is the extent to which there may be relations of complementarities and/or substitutability between young workers on one side, and women and old people on the other. Women's employment rates have rapidly increased also in Southern Europe where they were lagging behind; on the contrary, no systematic trend of old workers' employment has been in sight (fig. 9). The latter occurred despite the constant reminder of the European institutions in favor of increasing the employability of the "young elderly": ageing and low participation imply future scenarios in which the economic dependency rate-the ratio of persons not in the labour 
force to those in the labour force-could become hardly sustainable: according to the OECD economic dependency rates will rise from average $60 \%$ in 2000 to $75 \%$ in 2050. 


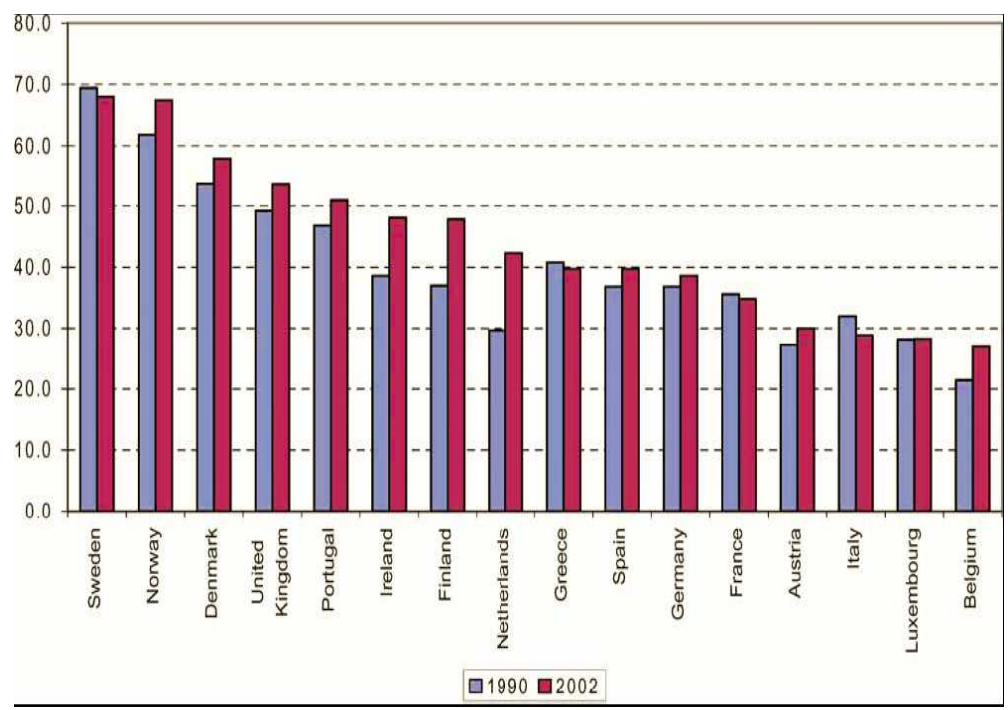

Fig. 9 Employment rates of elderly workers $(60+)$

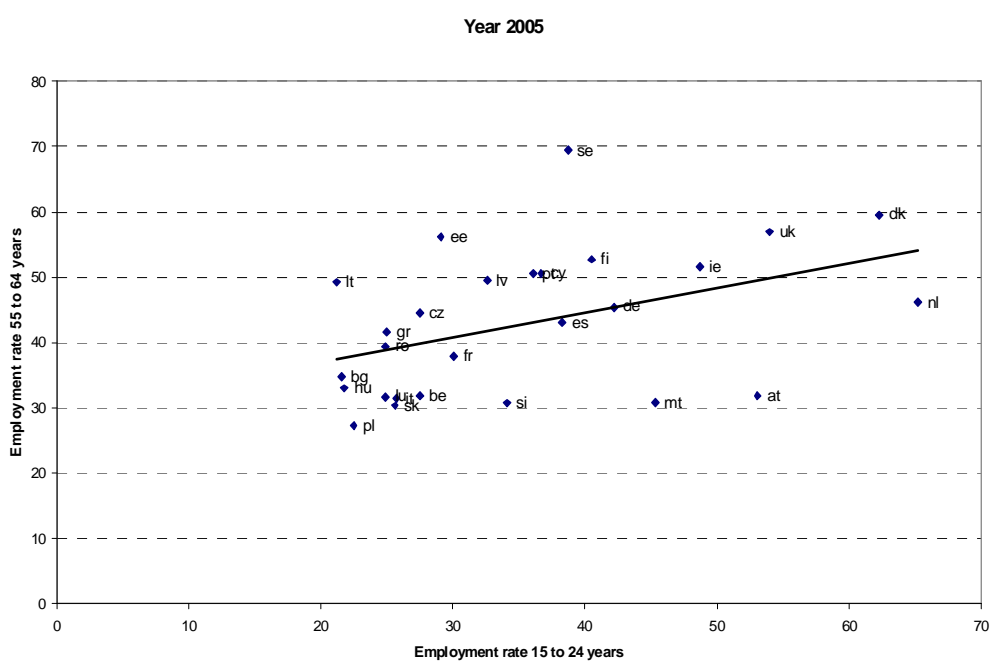

Fig. 10 Employment rates of young vs. old workers: 15-24 ( $x$ axis) vs. 55+ (y axis).

The idea that elderly workers and young workers might be efficient substitutes was (and perhaps still is) deeply rooted. Early retirement was advocated by many policy makers in the Eighties and Nineties as a remedy to facilitate employment for the young. And it has often been the object of negotiation with the unions with the intent of making room for young entries. Empirical evidence by A. Kapteyn et al. (2008) does not support the hypothesis and finds instead some minor complementarities, suggesting that discouraging early retirement will have no adverse effect on youth employment. ${ }^{12}$ Nor did J. Gruber, K. Milligan and D. Wise (2009) find evidence of the claim that there is a

\footnotetext{
${ }^{12}$ A. Kapteyn, A. Kalwij, K. De Voos, "Early Retirement and Employment of the Young" RAND Working Paper Series WR- 679 estimate a dynamic model of employment of the young, prime age and old people using panel data of 22 OECD countries over the time period 1960-2004.
} 
fixed number of jobs into which the young will move when older workers retire. The scatter-plot of youth (15-24) vs. older (55+) worker employment rates (fig. 10) confirms the hypothesis of weak complementarity rather than substitutability, a likely result of the growth of the service economy where the need for long opening hours requires part-time positions often filled by young people still attending school as well as women of all ages and older people.

A similar question relates to the potential competition between women and youth. Female employment has risen at remarkable speed since the Eighties: less in the Scandinavian countries where it has been historically high, much more in the rest of Europe. To what extent have women crowded out young workers in this process? Looking at growth rates of the last twenty years (fig.11), the substitution hypothesis cannot be disposed in the countries of Southern Europe, including France. Aside from the Netherlands outlier (where part-time employment has been vigorously facilitated to enhance women and youth employment), a modest negative association between female employment growth and the change of youth employment rates is visible. On the other hand, the very clear scatter plot of current women and youth employment rates (fig. 12) suggests a more articulated story: some substitution may have taken place since the Eighties, overlapping a situation in which already present complementarities were consolidated by the rapid contemporaneous growth of the service sectors. Here, the top performers (high on both counts) are, once again, Sweden, Denmark, Netherlands, UK, while the bottom ones are Greece, Italy, Belgium and France ${ }^{13}$.

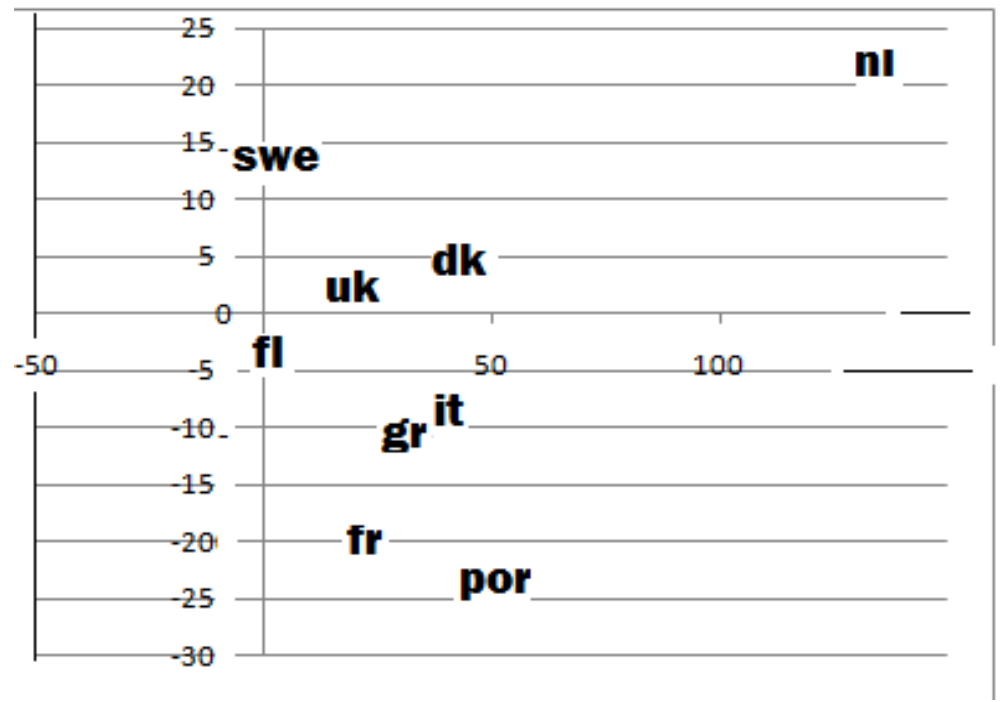

Fig. 11 Women employment growth WER (x-axis) and $\triangle Y E R$ (y-axis): 1987-2007.

\footnotetext{
${ }^{13}$ It is worth noticing that similar associations hold also across Italy's 20 regions: higher employment rates of young people are positively correlated with both older people and women employment rates: top performers are regions of the North, the least performing those of the Mezzogiorno.
} 


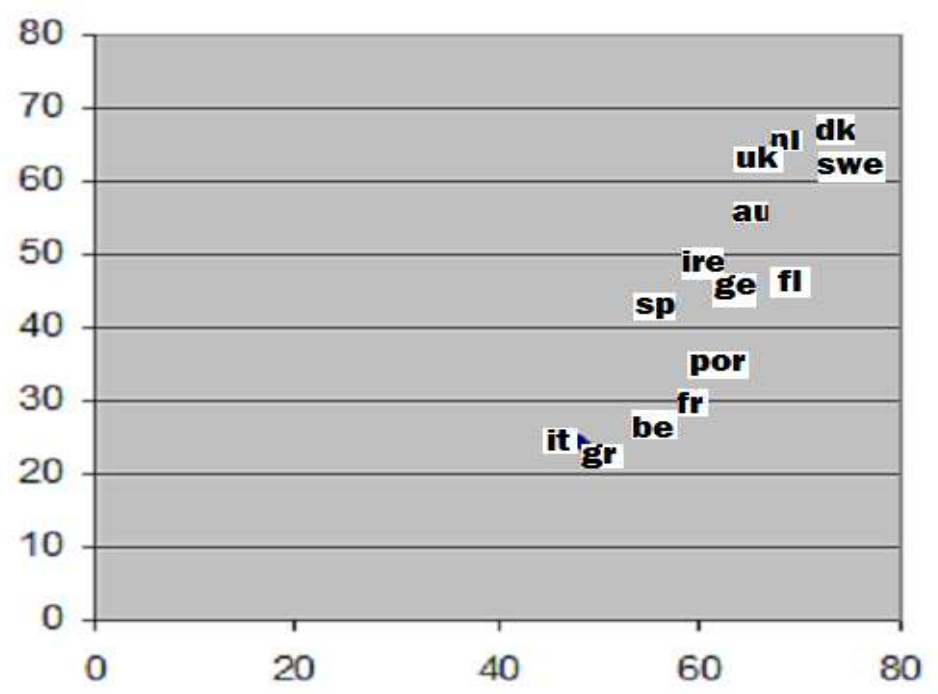

Fig. 12 Women WER and youth employment rates YER 2007

\section{The role of institutions}

Institutional arrangements have a crucial role in all the above developments. In this paragraph I show how existing institutional arrangements specific to the functioning of labor markets help to explain some of the cross-country differentials observed so far. A more general discussion of the interplay between institutions and performance is deferred to par. 7.

Women are at work where institutions help the reconciliation of working time with family duties and child care. Likewise, older people may prolong their working life where: (i) wage costs are held in line with productivity; (ii) retirement options are flexible; (iii) good practices of age management are in place. ${ }^{14}$ In this respect large differences exist, with the Scandinavian countries, Netherlands and France having achieved much higher standards than the rest of Europe. A rough but reasonable catch-all proxy of the extent of institutional involvement is provided by the share of social expenditure in GDP. Big social expenditure implies, inter alia, a relatively generous provision of child care, maternal leaves and old age care services, allowing women to participate to labor market activities which would otherwise be precluded by family chores. Fig. 13 shows a positive, although weak correlation between women's employment rate (WER) and social expenditure ${ }^{15}$.

\footnotetext{
${ }^{14}$ Good practices may take the form of flexible working times, reduced physically demanding tasks, retraining programs, redesigned workplaces and/or task rotation. In many EU countries public agencies provide advice and organizational consulting to firms willing to implement them (at times also limited financial benefits).

${ }^{15}$ In a few countries child care and domestic support aimed at helping women's work is provided directly by the employers: the leading country is the Netherlands with $41 \%$ of companies offering such services, followed by the UK with 17\%, while in the rest of the European area such percentages are much lower, in the order of 2 to $7 \%$.
} 


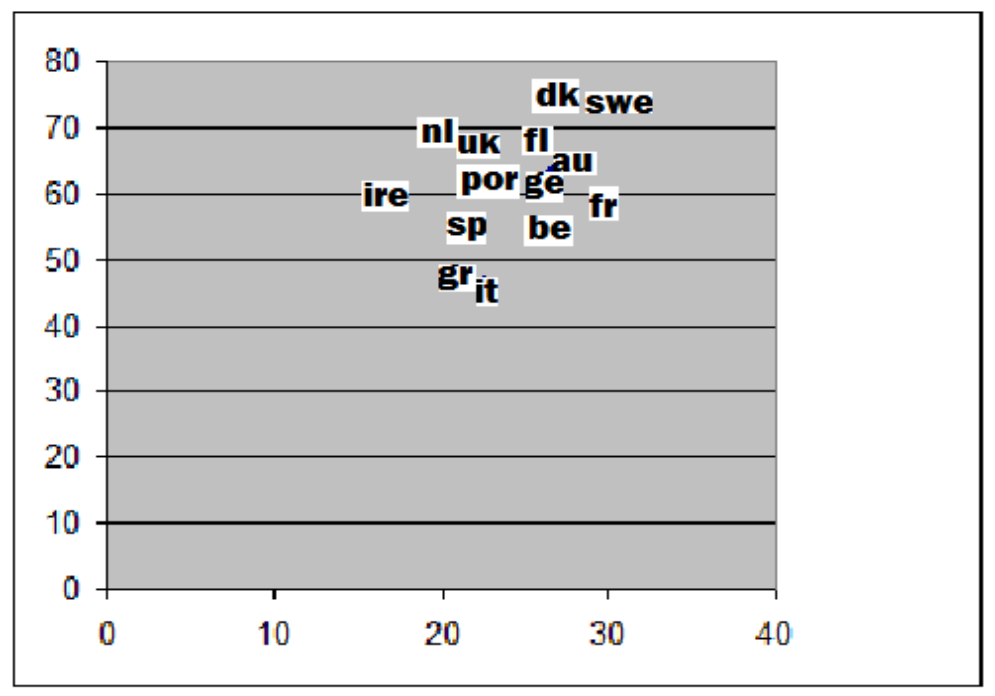

Fig. 13: WER (y-axis) and \% social expenditure in gnp (x-axis)

Much more striking is the positive correlation between the share of expenditure on care for the elderly (\% of GDP) and the employment rate of the elderly population (fig. 14).

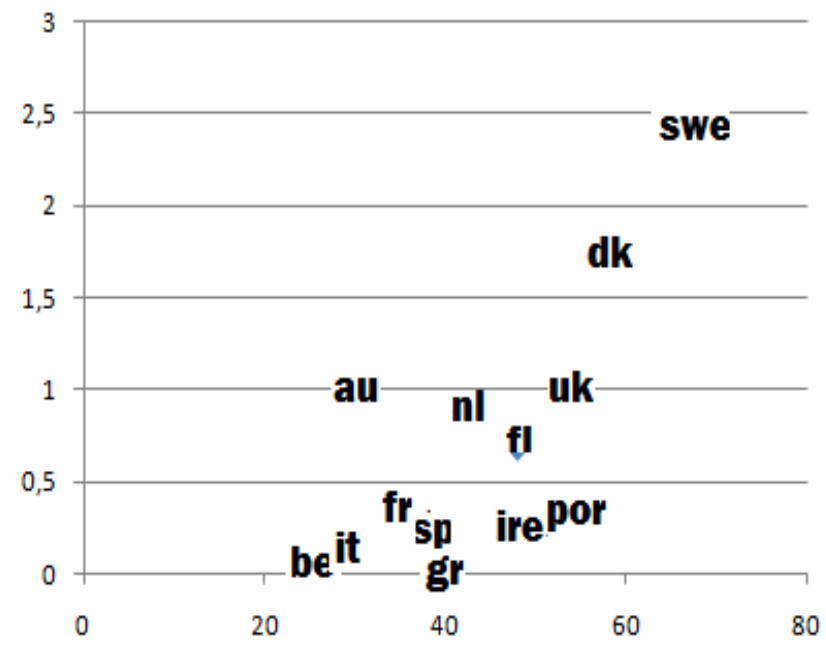

Fig. 14 Expenditure on care for elderly, \% gdp (y-axis) and elderly employment rate EER (x-axis)

Insights on the employability of elderly people come also from studies on earnings mobility ${ }^{16}$ : the employment rates of people $55+$ are positively correlated with the probability of downward earnings mobility (fig. 15). Downward mobility may be an acceptable option towards the end of working life in the presence of efficient safety nets, namely a sound welfare state that provides for the elderly. Unless - as is the case of the

16 B. Contini, "Earnings mobility and Labor market segmentation”, Laboratorio R. Revelli wp, 2003. 
U.S. and possibly other countries with very weak welfare systems - old people are forced to stay at work in order to make a living.

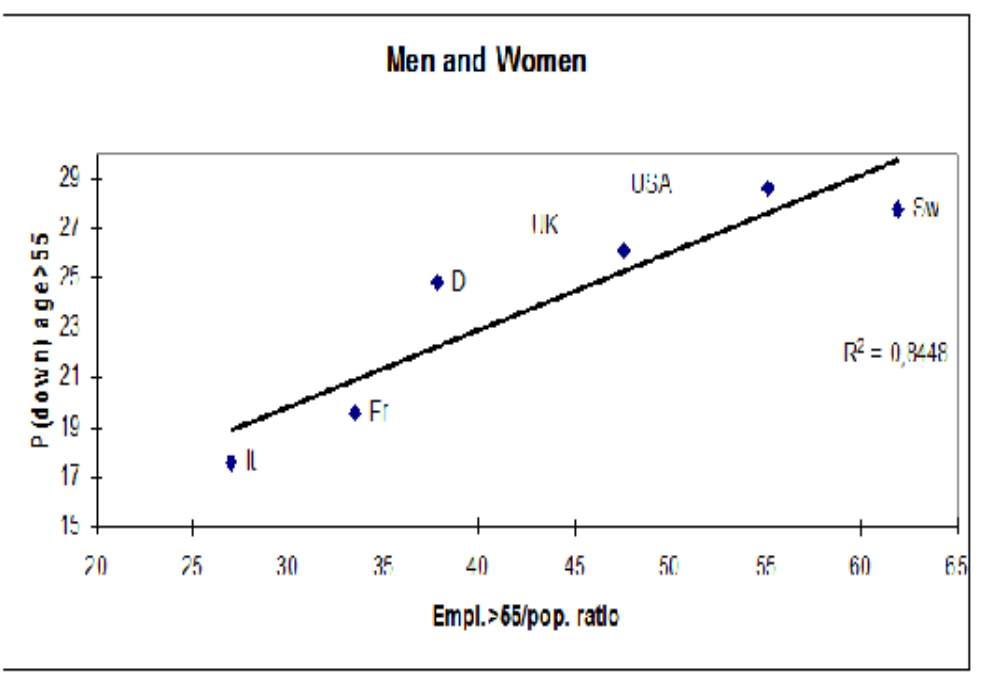

Fig. 15- Employment rates of 55+ (EER) vs. prob[downward wage mobility] at 55+

Institutions appear also in the explanation of youth employment: in fig. 16 youth employment rates are positively correlated with the share of ALMP expenditure in GNP.Once again Sweden and Denmark are the top performers, with Greece at the bottom of the list, and the UK as an interesting quasi-outlier. Welfare generosity is relevant also in other instances: consider the negative correlation between the share of long term unemployed with the maximum duration of unemployment benefits (fig. 17). This is a clear case of budget constraint: whatever the share of public expenditure allocated to alleviating unemployment distress, it is going to be relatively low where long term unemployment is frequent and vice versa.

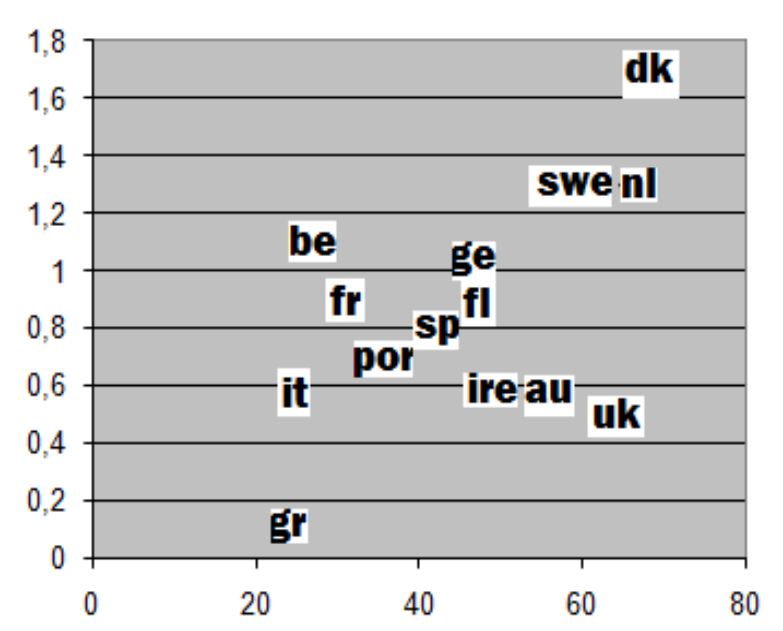

Fig. 16 Youth employment rate YER vs. ALMP \% expenditure 


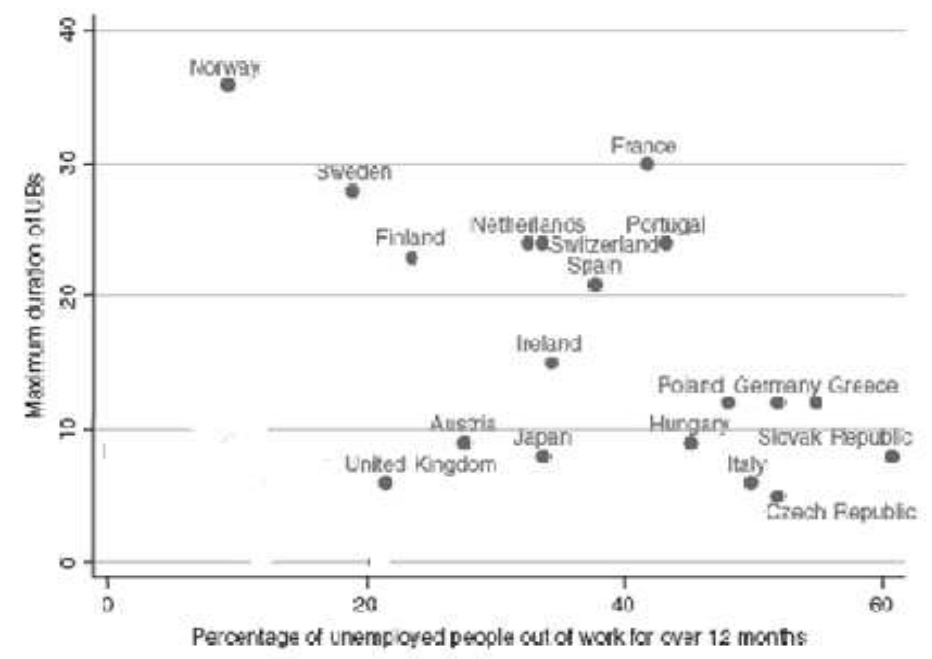

Fig. 17 Long term unemployment rate LTU (> 12 months) vs. maximum duration of unemployment benefits

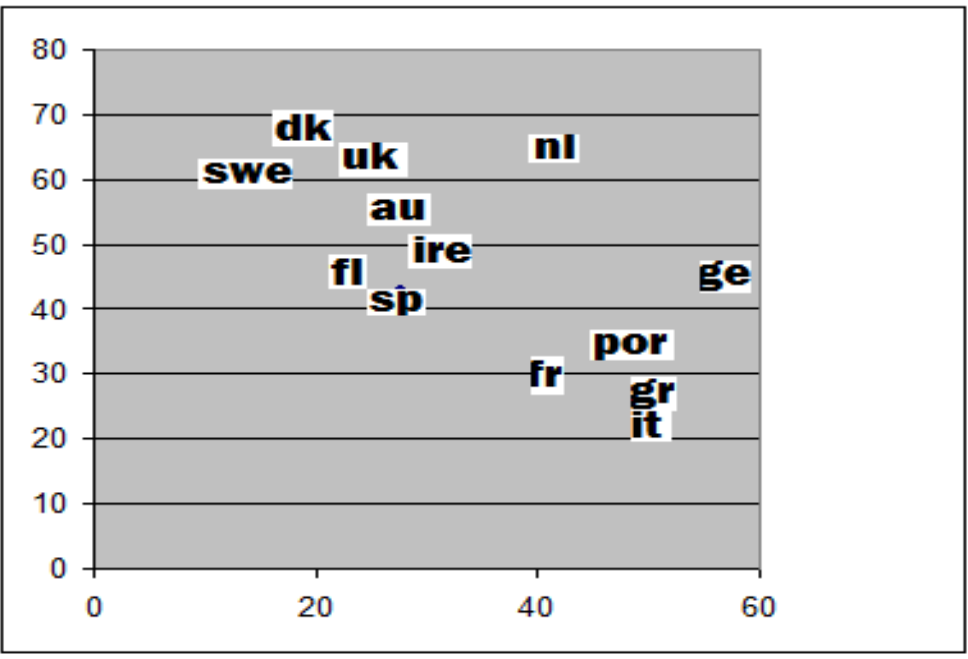

Fig. 18 YER (y-axis) and LTU long duration unemployment (x-axis)

A well known stylized fact of EU labor markets is the tight negative association between long duration unemployment (12 months + ) and youth employment (fig. 18). There is no obvious causal relation between the two, the best explanation running, again, in terms of institutional arrangements. In the countries where many young people are at work, retraining programs and public labor exchanges are run efficiently, and not by chance. Turnover may be high and unemployment spells frequent. But spells are short as the young people who lose their job are helped to get quickly back to work. On the other hand, in countries with low youth employment, turnover may be equally high, while public employment services are less effective, thus prolonging unemployment duration. Youth employment rates in Sweden and Denmark are above 60\% with the share of longterm unemployed at less than $20 \%$. A long way down the opposite end stand Italy and 
Greece, with France and Portugal at short distance. A similar argument explains also the negative association between YER and youth unemployment tout court (fig. 19): many of the long term unemployed are, in fact, young people.

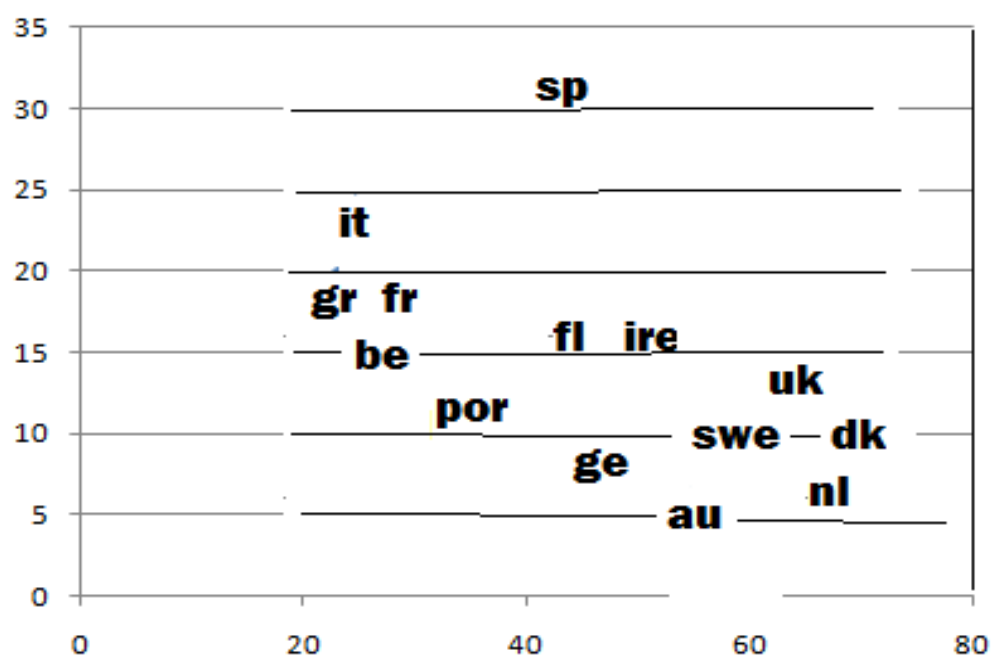

Fig. 19 - YER 2007 (x-axis) vs. YU youth unemployment rate 2007 (y-axis)

\section{Wage rigidity and youth employment}

The economists' classical explanation to the low employment rates of young people (and/or their high unemployment) is wage rigidity, and more specifically the failure of wages to adjust downwards. While measures of wage rigidity are not readily available (nor are minimum wages implemented in all EU countries), the ratio of adult wages to young people's wages provides an indicator of the relative cost of adult workers vis-à-vis their younger colleagues. The higher the relative cost of youth labor, the fewer the job offers to young people. Unfortunately it is impossible to single out how much of the differential is attributable to part-time and/or atypical jobs which are frequent among workers aged 15-24. With the above caveats, Fig. 20 shows a slight positive correlation between youth employment rates and the relative cost of adult workers to their young counterparts (wage 35+ / wage 19-24), a weak match with theoretical predictions. ${ }^{17} \mathrm{~A}$ different reading of the graph suggests that the well known divide between countries of Northern Europe (with Austria) with high YER in the upper part of the scatter and those of Southern Europe (with Belgium) with low YER, is proposed once again. Within each of the two groups of countries the expected positive correlation between YER and the adult/young wage differential emerges quite neatly.

\footnotetext{
${ }^{17}$ In the last decade the relative cost of adult vs. youth labor has increased in most of the EU, following the trend of rising wage differentials.
} 


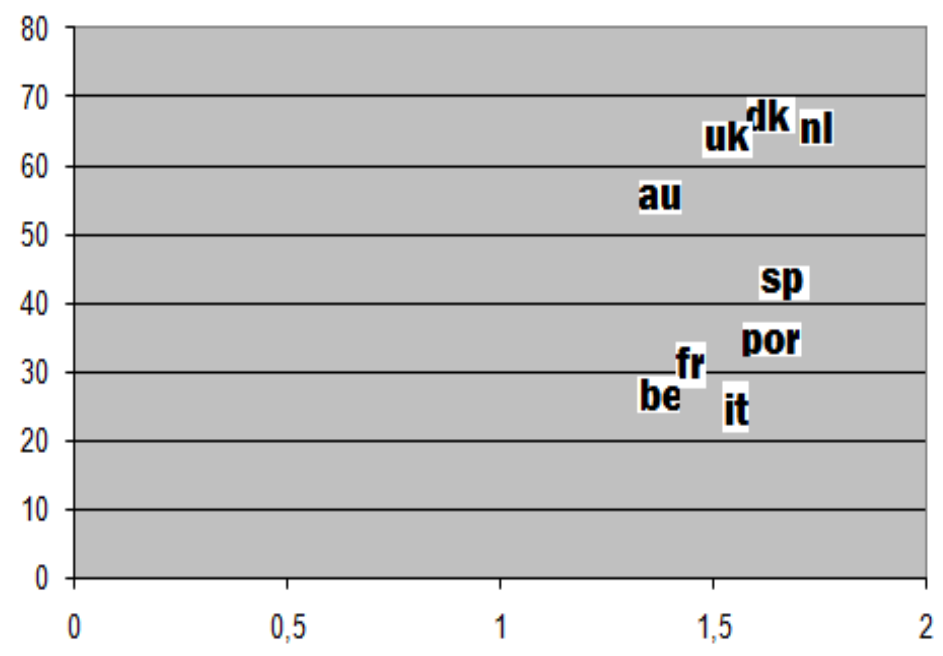

Fig.20 YER (y-axis) vs. the wage differential adult / young workers (x-axis)

\section{Mobility and flexibility}

In the previous paragraph I have argued that relative youth labor costs may, to some extent, contribute to explain youth employment differentials in Europe. Is there evidence that youth labor is also flexible and that such flexibility may also explain employment differentials? Flexibility refers to many different concepts: temporary jobs, fixed-term contracts, atypical positions, loose hiring and firing rules, disguised selfemployment and others too. Each of these may have diverse meanings and implications in different countries. Measuring flexibility is a slippery problem.

Flexibility is sometimes proxied by indicators of mobility. Boeri and Garibaldi (2009) suggest that increased mobility may explain the unemployment decline in the EU via the increase in job finding rates and the reduction in unemployment compensations. Mobility is measured by the unemployment inflow and outflow rates for EU15 as a proportion of the relative population at risk (fig.A5). After peaking during the 1992-93 recession, unemployment inflows would seem to have stabilized at a significantly higher level than the rates registered in the late Eighties (fig. 21). The argument is suggestive but somewhat weak in view of its aggregate nature. 


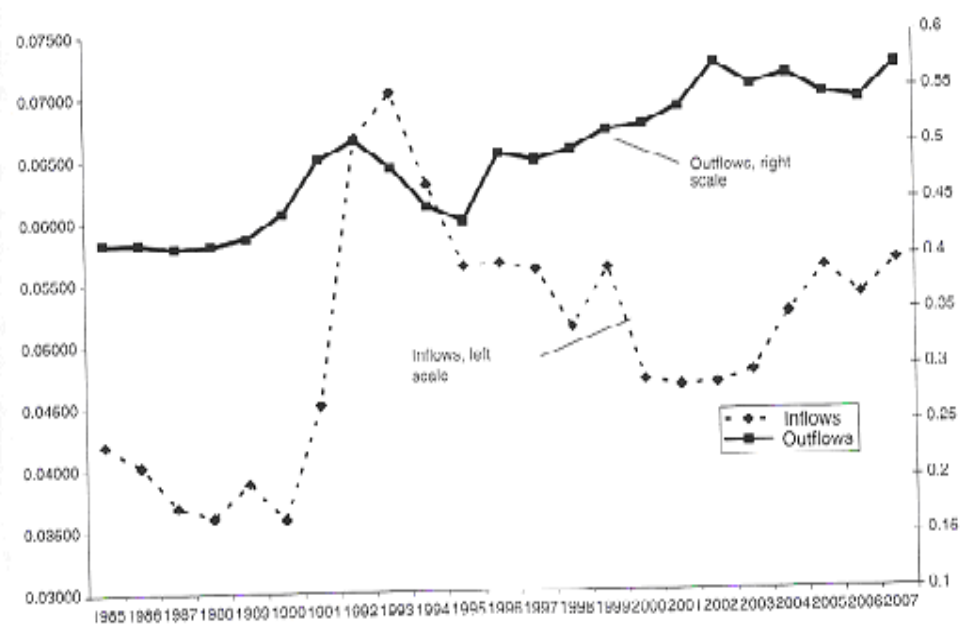

Fig. 21 Proxy unemployment inflows (as a percentage of employment) and outflows (as a percentage of unemployment).

Source: T. Boeri and P. Garibaldi(2008. Estimates based on the OECD Unemployment

Duration Database.

A direct look at country data on flexibility of working contracts, provided by the OECD makes a better option at this stage. Caution is, however, necessary: as already pointed out, definitions of temporary and part-time jobs are not homogeneous across countries, nor is it clear when the two overlap. ${ }^{18}$ I resort to a rough proxy of atypical jobs: the weighted average between the share of temporary positions and that of part-time jobs (ATYP). Fig. 22 suggests an expected positive correlation between ATYP as defined above and the youth employment rate. The Netherlands stands out with the Nordic countries as resorting most frequently to atypical jobs for the younger cohorts. Spain follows at short distance: recall that in the mid 90's generalized time-determined contracts were introduced, but a few years after the applicability of the new contractual forms was drastically reduced. As a matter of fact, in 2008 Spain still tops the list with young people in temporary positions (OECD definition) with a share of $58.3 \%$ on overall employment, after having receded from $68.6 \%$ in 2000.

\footnotetext{
${ }^{18}$ The OECD data dealing with flexibility are the following: shares of temporary jobs and part-time jobs on total youth employment, of dependent workers with short tenure (less than 6 and 1 months), of involuntary part-timers among the young.
} 


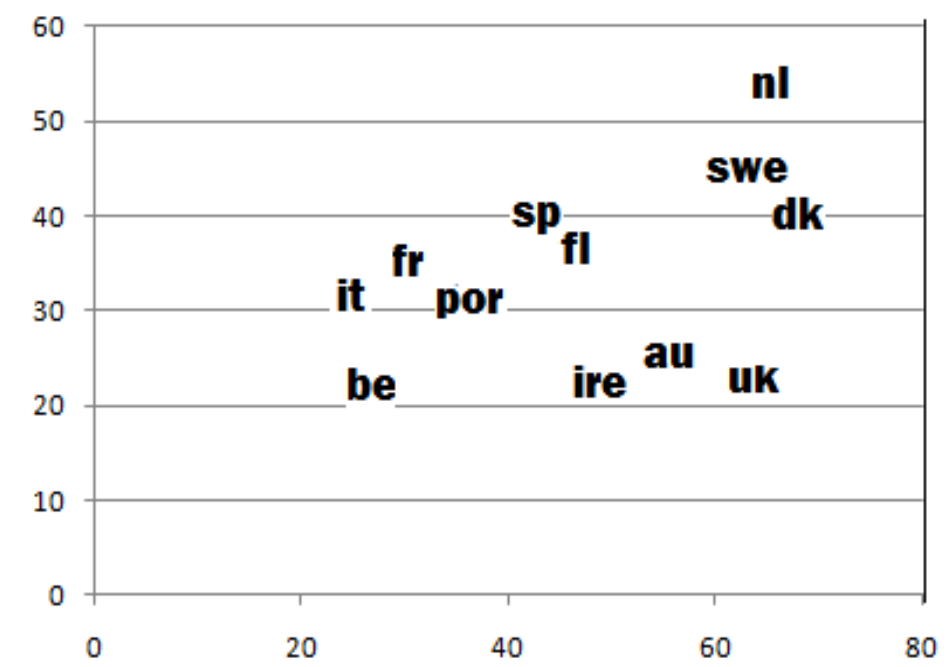

Fig. 22 YER (x-axis) vs. the share of atypical positions (ATYP) on youth employment (yaxis). Year 2007.

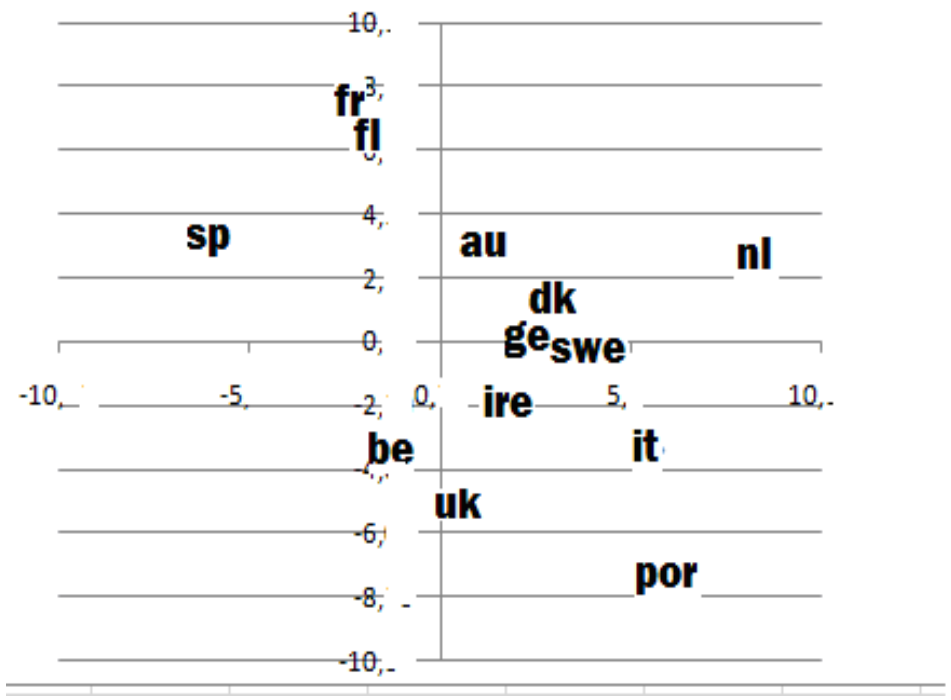

Fig. 23 SYER 2000-08 (y) vs $\triangle$ ATYP 2000-08 (x)

Surprisingly, however, the eight-year change 2000-08 in the share of atypical positions appears to be negatively correlated with the same change in YER (Fig. 23): perhaps a hint that the job creating potential of atypical contracts may have reached its peak a decade ago, and that in recent years some countries may have receded with some success (as Spain, and to some extent France and Finland) or may decide to follow suit in the not distant future (Portugal and Italy) ${ }^{19}$.

19 Recent face-to-face interviews with personnel managers of large Italian firms reveal that while the practice of hiring young people via atypical contracts is still widely utilized as a cost-saving device, serious doubts on their long run profitability are now being raised: the prospect of likely turnover at the end of the contract acts as a disincentive to serious engagement of the newly hired. They are often scarcely motivated, absentees, non-cooperative, despite the perspective of being reconsidered for an open-end position at the end of the contract if a good reputation is earned in the interim. 
Do flexible workers enjoy being on flexible jobs? Fig. 24 shows a positive association between the share of young people working on temporary contracts against the share of young involuntary part-timers. The high correlation does not imply that the same people who hold temporary contracts are also part-timers against their will. It is a hint, however, of labor markets where large number of young people have reasons to complain. Not surprisingly Spain is at the top of this malaise (despite the previously mentioned counter-reform), while the UK and Ireland, the least regulated EU countries, are in best position, with a relatively small share of temp contracts and also a low incidence of young involuntary part-timers.

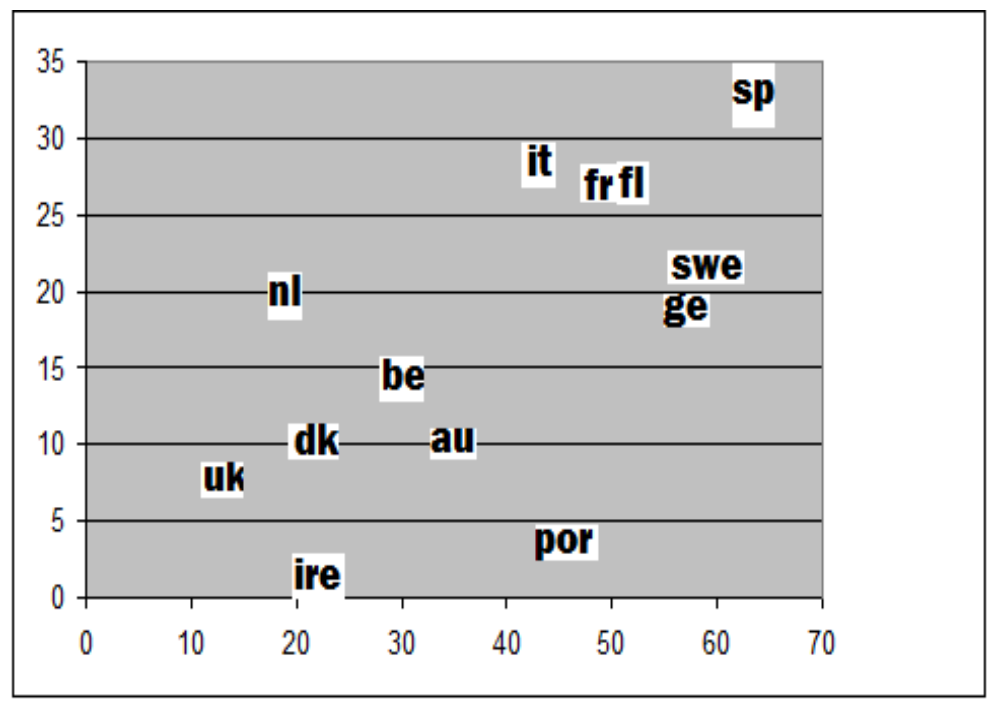

Fig. 24 Temporary jobs (x-axis) vs. involuntary part-time (y.axis)

\section{Are fixed-term contracts effective "ports of entry" to permanent positions?}

An important empirical question is raised in relation to flexibility and temporary jobs: are atypical, fixed-term contracts, effective stepping stones - "ports of entry" - to permanent positions? If this were the case, it would not be the cause of serious preoccupation. The evidence, based on single country evaluation studies, is mixed. In the UK Booth et al. (2002) find that temporary jobs pay less than permanent positions and yield lower satisfaction. In addition, work-related training is seldom delivered. Nonetheless, fixedterm contracts appear to be effective stepping-stones to permanent jobs. In Germany (Hagen, 2003) and in the Netherlands (Zijl et al,, 2004) temporary positions are found to increase both the re-employment probability as well as the chances to move to a permanent job. Several Italian studies suggest a positive, but very modest impact: (i) the probability of a 1-year transition from an atypical job to an open end position is only 15\%; the work-and-training subsidized 2-year contract (CFL $=$ Contratto di Formazione e Lavoro), implemented in the mid Eighties but almost phased out during the Nineties showed a better turnout (Berton et al., 2008); (ii) between $50 \%$ and $75 \%$ of the 
observable additional jobs would have taken place also in absence of the CFL- program; moreover, a non-negligible number of jobs of non-eligible workers (in their 30's) were offset by CFL hires (Contini et al., 2003); (iii) Gagliarducci (2005) finds that the probability of moving from a temporary job to a permanent position increases with the duration of the contract, but decreases with repeated temporary jobs and career interruptions; (iv) according to Ichino \& al. (2008) temp jobs are an effective springboard to permanent employment in Tuscany; (v) Picchio (2008) reports that temporary positions increase the probability of a 2-year transition to an open-end position by about 15 p.p. relative to one originating from unemployment. In contrast to the mixed (at best) European experience, some US studies pointed out negative effects on labour market outcomes or little indication of stepping-stone effects (Autor and Houseman, 2005).

\section{Institutions, social capital and performance}

The considerations of the preceding pages are based on cross-country "between" comparisons that evoke patterns whose convergence is unclear and might take place only in the very long run. The categories of traditional neo-classical growth economics fall short of explaining the deep causes of such patterns by only focusing on differences in the paths of prices, factor accumulation, and technological progress.

Institutions are natural candidates for explaining the roots of long-run growth and performance. In his Nobel lecture D. North defined institutions as “...a set of rules, compliance procedures and moral and ethical behavior designed to constrain the behavior of individuals...": as such they shape the incentives in economic production and exchange. But the channels through which institutions affect economic activity are still largely unexplored. One problem is that economic institutions are endogenous: they influence the redistribution of resources, and therefore they are influenced by conflict of interests and by political power. Undoubtedly the increasing unemployment during the Seventies and early Eighties led to changes in institutions as many EU governments tried to limit its rise. The literature has stressed the cross-country correlation between institutions and economic development (and I have here followed suit in relating the European institutions to labor market performance). But one of the issues is that of causality (Acemoglu et al., 2001 and 2004), whose immediate consequence is the empirical problem of identification.

The second aspect of institutions that deserves attention is the role of culture. Social capital, defined by the set of beliefs and values that facilitate cooperation among members of a community provides informal rules at least as important as the formal ones embedded in institutions (Guiso et al. 2004; Tabellini, forthcoming). The flexicurity strategy advocated by the European institutions to deal with the future of youth employment needs to take into account many of the issues discussed so far. As recently suggested (Algan and Cahuc, 2007 and 2009), building trust is a pre-requisite as well as a by-product of successful flexicurity approaches. 


\section{BOX}

Institutions come about when political perception of the problems is sufficiently mature. Italy provides an interesting example of institutional endogeneity. Fig. 25 shows the trend of separation rates from permanent, open-end positions in the 1986-2003 time window. There is a sudden increase of younger workers' separations in 1993, at least three years before the Pacchetto Treu, a law of 1996 aimed at introducing additional flexibility to the hirings of young people. The law has simply sanctioned or legitimized already existing trends.

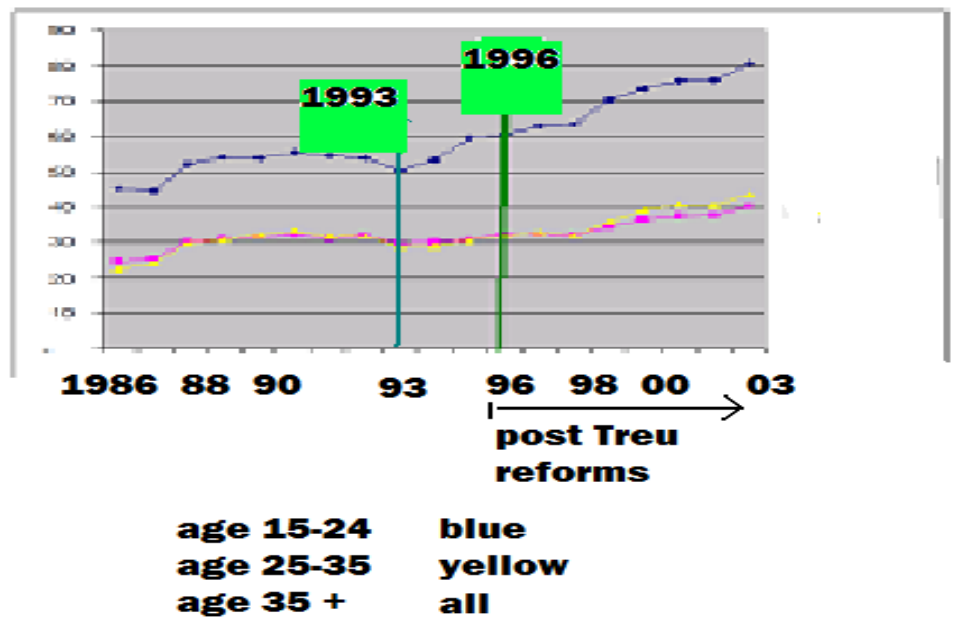

Fig. 25 Separation rates from open-end permanent positions: Italy 1986-2003.

The second aspect of institutions that deserves attention is the role of culture. Social capital, defined by the set of beliefs and values that facilitate cooperation among members of a community and provides informal rules, is at least as important as the formal ones embedded in institutions (Guiso et al. 2004; Tabellini, forthcoming). The flexicurity strategy advocated by the European institutions to deal with the future of youth employment needs to take into account many of the issues discussed so far. As recently suggested (Algan and Cahuc, 2007 and 2009), building trust is a pre-requisite as well as a by-product of successful flexicurity approaches. But building trust is a long, indeed gigantic task. The "right amount of trust" has been the object of preliminary but very suggestive inquiry (Guiso et al. 2006): “....in one group, the high trust North European countries, such as Norway, Denmark, Finland, Sweden and the Netherlands, the distribution (of trust) has a fat tail on the right and the modal level of trust is quite high. In another group - the Mediterranean countries and several Eastern European countries - the fat tail is t6o the left, denoting low average trust. In a third group including several EU countries (Austria, Germany, France and the UK) the distribution is more balanced with (intermediate) modal values...., and the distributions are more symmetric". This finding, which takes us back to G. Esping Andersen's classification of the Welfare States, is hardly surprising in the light of what I have argued in this paper. It closely matches all the rankings that have been so far reported. 
The World Bank provides an annual survey "the rule of law" of 219 world countries ranked according to the compliance with their own legal system: each score indicates the country's percentile rank. At the bottom of the list are found most of the poorest countries of the globe. All European countries rank above the 80-th percentile (Norway and Denmark stand at the top of the distribution), with the remarkable exception of Italy and Greece. I have plotted the EU country scores against the youth employment rates (fig. 26): not surprisingly, a clear positive correlation between the two indicators emerges, with Italy and Greece lagging behind all other countries. ${ }^{20}$ Here is another hint of how the institutions - via the rule of law - impact on labor market performance vis-àvis the weakest fringes of the workforce: the young in first place, but also the women and the elderly. Compliance with the law, accountability, control of corruption, regulatory quality, all contribute to strengthen the credibility of the institutions and the confidence entrusted by the constituency. ${ }^{21}$ Tax compliance is a natural economic indicator of such confidence : where tax evasion is high, the welfare state is weak. And a weak welfare system will fail to provide solid bases to the institutions that enhance the employability of the weak fringes of the workforce.

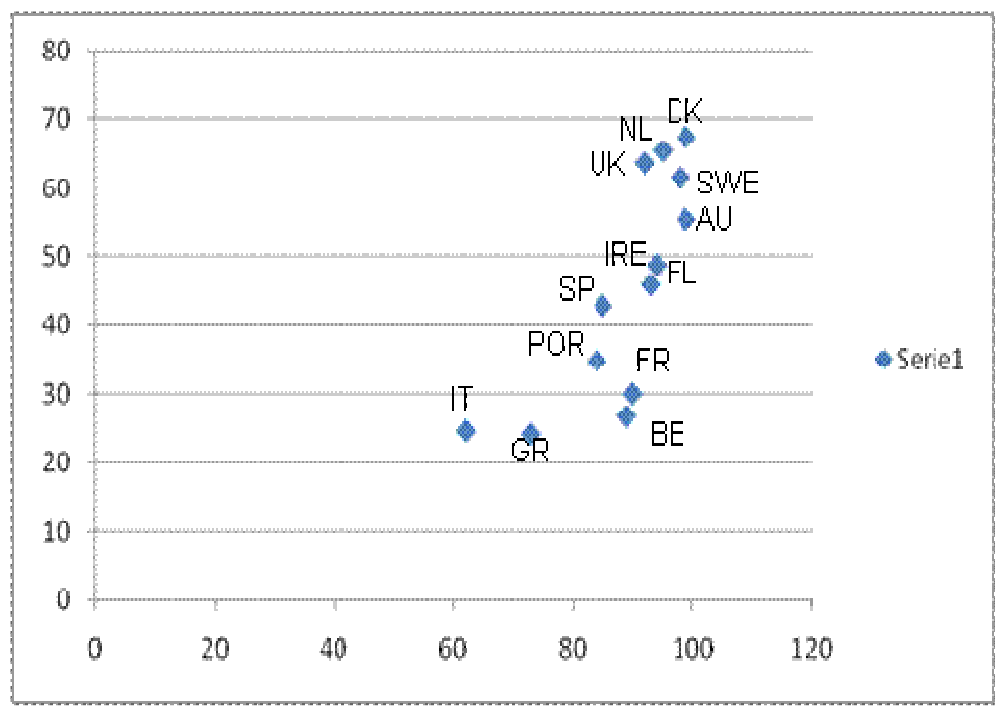

Fig. 26 - YER (2007) vs. Rule of Law

The tax compliance -non compliance game has a similar structure to the prisoners' dilemma: each citizen faces the same payoff and is liable for the same tax. The cooperative solution will emerge only if all comply: the payoff is big and available to all in the form of benefits from the welfare state. But the individual incentive to free ride is large. Hence the cooperative solution is not a stable equilibrium. The non-cooperative and stable equilibrium of the game is for all to evade: as a consequence there will be no welfare system and the payoff is low for all. If the "rule of the law" is missing, the noncooperative solution is doomed to prevail. The institutions can change the payoff structure by introducing appropriate sanctions and benefits, but this too may fail to

\footnotetext{
${ }^{20}$ As the jurists put it, the "law in the books" is quite a different matter from the "law in action".

21 The World Bank provides annual indicators also on these related items of the Rule of the Law: Not surprisingly, all rankings are highly correlated.
} 
restore the incentive to free ride. The only way by which the institutions may affect the outcome of the game is by restoring or building confidence altogether. If the effort is successful - but, as already pointed out, the task is gigantic - the incentive to play noncooperatively may decrease to the point where the cooperative solution becomes viable.

In the Mediterranean countries of the EU the irregular (black, unofficial) economy has traditionally been large, a consequence of economies where small firms play a major role, self-employment is high, open and disguised unemployment big, and, most of all, tax evasion is pervasive and sanctions rarely implemented. The negative correlation between the size of the irregular economy and the rule of law is evident and selfexplanatory (fig. 27). The negative correlation between the size of the irregular economy and the protagonist of our story, the youth employment rate (fig. 28) is a consequence of the two above, but it deserves to be discussed in its own right. Many young people, national or migrants - for that matter not only young people - who find it hard to find a job in the regular economy, will easily be attracted in the area of black or grey activities where the rule of law is weak. In the irregular economy pay is low and job security inexistent, the border line between legality and illegality is frail and dangerous (but earnings may be high in the world of outright criminal activities). Nor will these individuals report to have a job to the LFS interviewers. ${ }^{22}$ If retraining programs and public labor exchanges were run efficiently, unemployment benefits and/or safety nets of some sort available, the institutions would gain credibility and youth employment rates might not look as bad as they do. This is not a defense of the black economies, nor does this imply that illegal activities are a beneficial and effective safety valve against overt unemployment and high poverty. They are, in fact, a sort of safety valve that relieves from "private" poverty at outrageous risk (of life for those in criminal activities like the mafia, but also for those employed in many activities - illegal construction is the most obvious - where the most elementary safety measures may be absent), and disastrous from a collective perspective: profound distrust for the institutions and distance from democratic values, sheer illegality in all aspects of life, no incentives to education, tax evasion, obstacles to free economic competition and technological change. From this perspective it is disappointingly easy to conclude that the negative macroeconomic performance of Spain and Italy presented at the beginning of this paper is a consequence of such perverse dynamics, and not at all its cause.

\footnotetext{
${ }^{22}$ In the poorest neighborhoods of Naples estimated youth unemployment is close to $40 \%$, with the extent of the black economy also known to be at its highest. In the banlieus of Paris the situation may not be very different.
} 


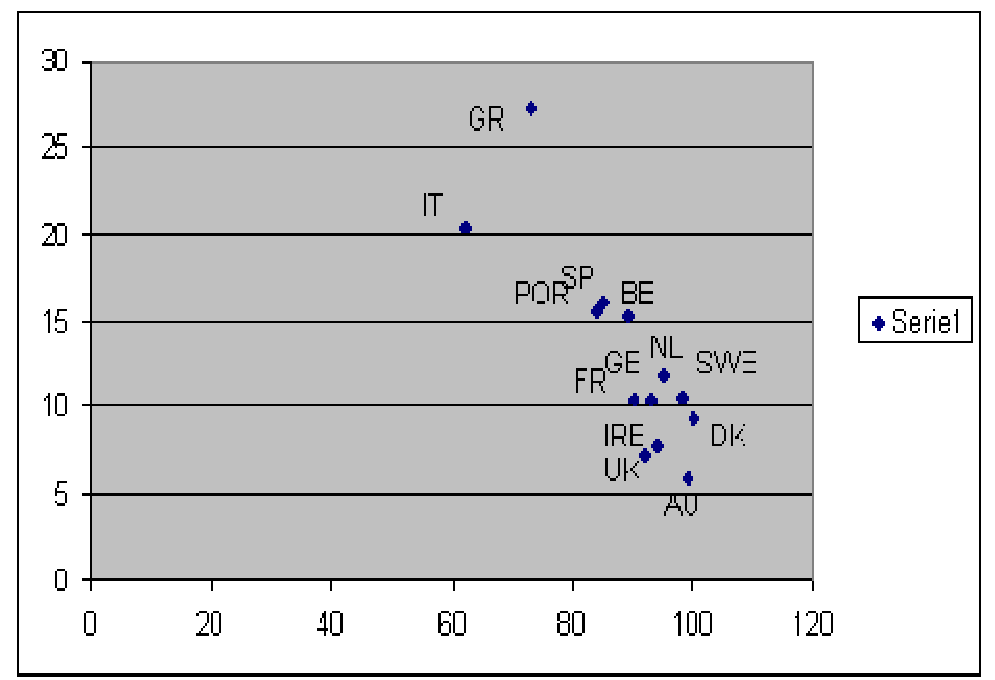

Fig 27 IRR = irregular economy (y) vs. Rule of Law (x)

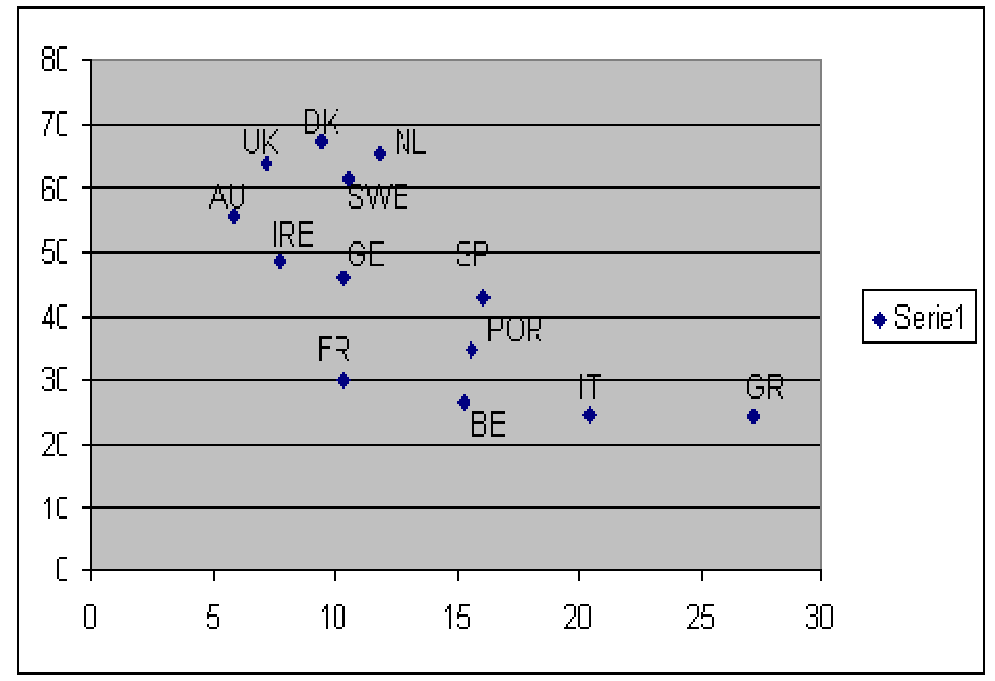

Fig. 28 YER 2007 (y-axis) vs. IRR (x-axis) 


\section{Conclusion}

Does this exploration suggest policy measures that may have an impact on youth employment in countries (especially of Southern Europe) where it looks most problematic? And where they might exert such impact in somewhat less than biblical times ? Authoritative economists have acknowledged their modest success. O. Blanchard has recently (2006) asked a courageous question “do we know enough to give advise?". My own - very modest - answer cannot be but disappointingly negative: we are dealing with persistent and structural patterns, difficult to reverse without drastic reforms of the labor market and of the welfare institutions, and not simply reforms at the margin, as many that have been implemented for decades. But drastic reforms need constituencies that will strongly support them. Unfortunately, very few are in sight.

\section{Bibliography}

Acemoglu, D., Johnson, S. and Robinson, S. (2004), Institutions as the fundamental causes of economic growth, MIT Working Paper.

Algan, Y. and Cahuc, P. (2009), Civic virtue and labor market institutions, American Economic Journal, vol. 1.

Autor D. and S.Houseman (2006), "TEMPORARY AGENCY EMPLOYMENT AS A WAY IOUT OF POVERTY?". in R. Blank et al. (eds.) Working but poor: how economic and policy changes are affecting low-wage workers, New York: Russell Sage

Bean, C. (1994), "European unemployment: a survey”, Journal of Economic Literature, 32 (2).

Bentolila, S. and G. Bertola (1990), "Firing costs and labor demand: how bad is Eurosclerosis ?”, Review of Economic Studies, 57.

Bertola, G., Blau, F. and Kahn, L. (2002), Comparative Analysis of Employment Outcomes: Lessons for the United States from International Labor Market Evidence, pp.159-218, in A. Krueger and R. Solow (eds.), The Roaring Nineties: Can Full Employment Be Sustained?, Russell Sage and Century Foundations.

Berton, F., F. Devicienti and L.. Pacelli (2008), " "are temporary jobs a port of entry into permanent employment? Evidence from matched employer-employee data", W.P. no.79

Blanchard, O. and L. Summers (1987). "Hysteresis in Unemployment", European Economic Review.

Blanchard, O. and Landier, A. (2001), The Perverse Effects of Partial Labor Market Reform: Fixed Duration Contracts in France, NBER Working Papers 8219, National Bureau of Economic Research, Inc.

Blanchard, O. (2006), European unemployment, Economic Policy, no. 45.

Boeri, T. and Garibaldi, P (2009), Beyond Eurosclerosis, Economic Policy.

Booth, A., 'Temporary Jobs: Stepping Stones or Dead Ends?' with M Francesconi

and J. Frank, June, The Economic Journal, 112, F189-F213, June.

Bruno, M. and J. Sachs (1985), Economics of World-wide Stagflation, Harvard Univ. Press

Calmfors, L. and J.. Driffil (1988). "Centralization of wage bargaining and macroeconomic performance". Economic Policy.

Cockx, B. and M. Picchio ( 2009). "Are short-lived jobs stepping stones to long-lasting jobs?," CESIFO W.P. Series

Contini, B. (2006), Earnings mobility and labor market segmentation, LABORatorio R. Revelli, Working Paper. 
Gagliarducci, S. (2005), “The dynamics of repeated temporary jobs”, Labour Economics, vol. 4, n. $12,429-448$

Gruber, K. Milligan and D. Wise (2009) "Introduction to Social Security Programs and Retirement Around the World: The Relationship to Youth Employment," in J.Gruber et al. (eds)., Social Security Programs and Retirement Around the World: The Relationship to Youth Employment, University of Chicago Press

Guiso, L., Sapienza, P. and Zingales, L. (2004), The role of social capital in financial development, American Economics Review, vol. 20(2).

Guiso, L., Sapienza, P. and Zingales, L. (2006), Does culture affect economic outcomes ?, Journal of Economic Perspectives, vol. 20 (2).

Helpman, E. (ed.) (2008), Institutions and Economic Performance, Harvard University Press.

Kapteyn, A. Kalwij, K. De Voos, "Early Retirement and Employment of the Young" RAND Working Paper Series WR- 679

Ichino, A. "Temporary Work Agencies in Italy: A Springboard to Permanent Employment?" (with F. Mealli and T. Nannicini), Giornale degli Economisti, September, 64(1), 1-27.

R.Layard and S. Nickell (1999), "Labour market institutions and economic performance”, in O. Ashenfelter and D. Card (eds.), Handbook of Labor Economics, vol. 3B, North Holland.

Lindbeck, A. and D. Snower (2001), "Insiders versus Outsiders", Journal of Economic Perspectives, vol. 15 , no. 1.

S. Nickell (1997), "Unemployment and labour market rigidities: Europe vs. North America", Journal of Economic Perspectives, 11 (3).

Nickell S., Nunziata, L. and Ochel, W. (2005), Unemployment in the OECD since the 1960's. What do we know?, Economic Journal, vol. 115.

North, D.C. (1990), Institutions, Institutional Change and Economic Performance, Cambridge University Press.

OECD (1994), The OECD Jobs Study: Evidence and Explanations, Paris, OECD

Tabellini, G. (forthcoming), Culture and institutions: economic development in the regions of Europe, Journal of the European Economic Association.

\section{Glossary}

YDR $=$ youth dependency ratio (age 16-24)

YER = youth employment rate (age 16-24)

$\mathrm{SCH}=\%$ attainment of secondary education on 15-24 age group

WER $=$ women employment rate

EER $=$ elderly employment rate $(55+)$

$\mathrm{ALMP}=\%$ active labor market programs on GNP

LTU $=$ long term unemployment rate $(12$ months +$)$

$\mathrm{YU}=$ youth unemployment rate (15-24)

ATYP = share of temporary and/or part-time jobs on employment

$\mathrm{IRR}=$ share of irregular employment activities on labor force 